\title{
La comunidad judía de Tetuán (1881-1940). Datos sociológicos en el libro registro de circuncisiones de R. Yishaq Bar Vidal Ha-Serfaty
}

\author{
ana María lópez Álvarez *
}

RESUMEN

Este artículo, cuyos datos básicos han sido extraídos del Libro registro de Circuncisiones de Rabi Yishaq Bar Vidal Ha-Serfaty, manuscrito aljamiado hebreo-español y haquetía, que se encuentra en el Museo Sefardi de Toledo, intenta ser una aportación al conocimiento de la historia de la comunidad sefardi de Tetuán en Marruecos, entre los años 1881-1940. Consta de una introducción histórica sobre esta comunidad durante el periodo que abarca este manuscrito, una descripción del mismo, así como un estudio biográfico de su autor, rabino de esta comunidad entre 1880 -

1941, el cual nos proporciona una serie de datos de natalidad, onomástica, lengua, oficios y trabajos,

\section{ABSTRACT}

This paper intends to contribute to the knowledge of the Sephardic community in Tetuan, Maroc, between the years 1881 and 1940. Its basic data have been drown out of the Register Circumcision Book by Rabi Yishaq Bar Vidal Ha-Serfaty from Tetuan, an aljamiado manuscrpt in Spanish-Hebrew and Haquetia, which is at the Sephardic Museum in Toledo. The paper consists of a historical introduction about that community along the period covered, followed by a descrption of the manuscript, as well as a biographic study of the author, rabbi of the community between 1880 and 1941. The manuscript provides a number of data about birth rate, onomastics, language, jobs and

* Doctora en Filología Semítica. Directora del Museo Sefardí de Toledo, Cuerpo Facultativo de Conservadores de Museo. 
emigración y otros detalles, que nos permiten conocer desde su interior, al analizar una fuente sefardí, la evolución de esta comunidad durante el periodo citado.

\section{PALABRAS CLAVE}

Mellah, shekh, mohel, rabino, Tetuán. rades, emigration and further details which let us know the community development, from the inside, in analyzing a Shephardic source.

\section{KEY WORDS}

Mellah, shekh, mohel,rabbi, Tetuan.

\section{INTRODUCCIÓN HISTÓRICA}

Los rasgos que definen la comunidad judía de Tetuán desde finales del siglo $\mathrm{XIX}$ y durante los primeros cuarenta primeros años del siglo $\mathrm{XX}$ son: los de unia inestable situación política, pobreza, fuerte emigración y una dedicación al sector primario en su economía. A finales del siglo xix y pese a las promesas del sultán, se produjeron constantes casos de violación de los derechos de los judíos en Azemmour, Alcazarquivir, Entifa, Arzila, etc. Ante las quejas de la comunidad, no sólo no se tomaron medidas para evitar estos asesinatos, sino que se alegaba que los judios eran los causantes de todos los males que le acontecian a la comunidad árabe y que si solicitaban la protección de las potencias extranjeras era para escapar a la justicia marroquí pues no tenían en consideración que cuando todos les expulsaban, Marruecos les había acogido:

"Se evalúa en 300.000 el número de judíos que habitan Marruecos, pero ya una parte muy pequeña de éstos continúa bajo la jurisdicción marroqui. Los demás, después de permanecer o en España para procurarse el derecho de nacionalidad, se han sustraido a la soberanía del Sultán. Los judios ricos o que poseen alguna fortuna, ni siquiera tienen que hacer ese viaje; les basta dar una pequeña cantidad en la oficina de alguna Legación - Consulado europeo, para gozar de la protección, a fin de no pagar impuestos y no estar sometidos a las autoridades del país. Los comerciantes marroquís aprovechan la posición de estos judíos, haciéndoles entrar como falsos asociados en sus razones sociales, para sustraerse de este modo al pago de contribuciones. Naturalmente este estado de cosas es muy odioso al Sultán, el cual tiene la intención de prevenir a los judíos que si en cierto tiempo no se someten a la soberanía marroquí, serán expulsados del territorio. Sin embargo, esta determinación no puede llevarse a cabo sin el consentimiento de las representaciones de las potencias que les han concedido su protección”'.

M. Fernandez Rodriguez, España y Marruecos en los primeros años de la Restauración (1875-1894). Madrid, CSIC, 1985. págs. 234-234. 
Se presentaron por parte de algunas autoridades extranjeras, en especial de Italia, protestas que no produjeron ningún resultado.

En el año 1862 se había instalado en Tetuán la escuela de la Alliance Israelite Universelle (Alianza Israelita Universal, AIU), que se preocupó de conseguir una mejor preparación de los judíos de Tetuán y del resto del Norte de África. Desde esta institución se intento paliar la pobreza de la comunidad y en especial la ignorancia femenina.

Algunos hechos destacados se produjeron a finales de siglo y que es necesario comentar porque nos dan un mejor conocimiento de esta comunidad, hechos que rompian la vida interna de la comunidad preocupada por asaltos y violaciones. En 1882 un hecho conmocionó a la comunidad y tuvo por protagonista a J.B... quien en una ceremonia sinagogal había insultado a $R$. Shemtob Benwualid porque éste a la hora de las bendiciones no había alabado con suficiente encomio a un hijo suyo que era juez, lo que había ofendido a su padre. El Tribunal Rabínico, había decretado la excomunión contra J.B... El incidente fue tan grave que incluso el dia de Shimhah Torah (Alegría de la Ley), un soldado había irrumpido en la sinagoga de R. Shmuel Nahón solicitando que se levantase el la excomunión, a lo que se respondió que una decisión del Tribunal era inamovible. Este mismo hecho se reprodujo en la de Shemtob Benwualid con idéntico resultado, lo que provocó la ira de Juan Murphy, cónsul de España a quien J. B..., había expuesto su caso y que había tomado partido por él. La violación de los centros de oración en Shimhah Torah donde el cónsul habia entrado acompañado de su perro y con un cigarro en la boca, motivaron que las quejas llegasen hasta el Gobernador, quien se desentendió por tratarse de un tema propio de la comunidad. Cuando salieron del palacio, J. B... y el cónsul la multitud enfurecida atacó al primero. Era un hecho de tremenda gravedad por tratarse del día festivo antes mencionado. Sólo el buen sentido del vicecónsul de Portugal y de algunos miembros de la comunidad pudo devolver la calma.

Otro factor importante de la vida comunitaria fue la emigración que fue la tónica general; la vida era cara en Tetuán y había que buscar otras fuentes de riqueza. Primero en el entorno: Ceuta, Orán, Gibraltar, sur de la Península, y más tarde Brasil, Argentina y Venezuela, serán los lugares elegidos para esta emigración.

A finales del siglo $x \mid x$, el ministro de Francia visitó Tetuán ${ }^{2}$, lo que despertó gran interés en la comunidad. Sin embargo en el discurso pronunciado ante las autoridades locales M. Feraud dijo que:

Enrique Taviel de Andrade, Cuestión de Marruecos, Madrid, 1888. Capítulos VI y VII, págs. 81-91. 
"los israelitas de Marruecos eran muy recalcitrantes y que debian sen. tirse como huéspedes en el pais y no incomodar a los árabes que son los propietarios" 3 .

Aunque después visitó la escuela y quedó sorprendido del nivel de los alumnos e intentó atenuar sus palabras indicando que había dos grupos, el de los judíos descendientes de los españoles y el de los que se encontraban ya en Marruecos equiparable a los beduinos y por tanto menos cultos y preparados, el mal ya estaba hecho.

A pesar de la inestable situación política, el Sultán se dio cuenta del afecto que le tenían sus súbditos judíos y así escribió una afectuosa carta a los judios de Tánger agradeciéndoles sus regalos y buenos deseos ${ }^{4}$ y manifiestándoles cuanto «le ha halagado la conducta de los hebreos, a los cuales creía erróneamente emancipados de la autoridad imperial a causa de la protección ejercida por las potencias extranjeras" ${ }^{5}$. Este afecto se confirmó en la visita a Tetuán del Sultán Muley Hassán. Aunque al principio la visita no les fue favorable ya que no se les incluyó en el protocolo, al final, la víspera de su partida y después de abonar una serie de propinas y de costear un regalo fueron recibidos por el Sultán. La entrevista transcurrió con toda normalidad y el Sultán y «mostró una gran satisfacción de entrevistarse con los judíos y un gran deseo de agradarles". La impresión de la visita en la población musulmana fue grande. Un gran paso moral se había dado. El Sultán se había preocupado por el tema de la vinculación del terreno de la escuela al mellah ${ }^{6}$ y encargo al gobernador

3 Sarah Leibovici, Chronique des Juits de Tétouan (1860-1896). París, 1984, pág. 173.

4 Enrique TAVIEL dE ANDRADE, Cuestión ... op. cit., págs. 187-188: ... "agradece mucho la lealtad de los israelitas que no se olvida que son sus subditos, a pesar de estar protegidos por las potencias extranjeras. Añade SM sherifiana que la prueba de adhesión ostensiblemente manifestada por los hebreos le regocija en extremo porque prueba la sumisión del pueblo que sigue permaneciendo fie! a las costumbres de sus antepasados. Aconseja el Sultán a los israelitas que perseveren en su fidelidad, pues de este modo se harán dignos de su benevolencia". "Pide a Dios que conceda sus favores a la comunidad, a cuyos miembros desea salud, riqueza y prosperidad y una tranquila y larga vida bajo el dominio imperial».

5 Enrique TAVIEL dE ANDRADE, Cuestión ... op. cit. pág. 188.

- Barrio judío. ENCICLOPEDIA Universal llustrada europeo americana. Tomo LXI, Madrid, Espasa Calpe, 1928: “En el Melaj o Mellah (el Saladero) ...lo forman dos calles paralelas, rectilineas, cortadas perpendicularmente por otras más estrechas; algunas cubiertas, todas muy aseadas... limitado por la acequia o Sakia el Fokia, y por ofro accidente del terreno que dio origen a la calleja de las Maidas. Empezó la colonia a estąblecer sus viviendas en el llamado hoy barrio de La Meca, sitio conocido por Riat de Ersini, que se comunicaba con La Mesal-la, y levantó su muro desde ésta hasta el Gurna..., sirviendo también de divisoria hasta las Sakıa el Fokia un terreno alto que hoy forma el lateral del E. de los Tarrafin. Debajo de éste se formó otro barrio llamado Judería, en el que estuvo el lugar de El Prado, que aún se recuerda por una higuera secular perteneciente a una casa que sirvió de primitivo convento-hospital cristiano. Los apellidos Pariente, Toledano, Taurel o 
estudiarlo. Todos los gastos y sufrimientos de las vísperas se daban por bien empleados. Hasta noviembre de 1891 no se pondrá la primera piedra de la nueva escuela que se inaugurará en 1994.

La parte peor de la vida de la comunidad la llevaban las mujeres que desde Hanukkah hasta la vispera de la fiesta, trabajaban duro en Tetuán. A todo esto se unía el cuidado diario de los hijos y del hogar. La preparación del pan ácimo para la fiesta de la Pascua era realmente trabajoso. También que había que blanquear la casa e incluso se pintaban los marcos de puertas y ventanas una vez al año. Esto motivará que años más tarde se hable de que las casas de la judería de Tetuán llamaban la atención por su limpieza y blancura ya que los habitantes encalaban las casas y ponían una linea roja como adorno en el suelo ${ }^{7}$. Era tan dura la situación de la comunidad, que el director de la escuela de la Alliance, viendo las necesidades de la misma, tomó la decisión de contactar con los emigrados tetuaníes en América solicitando su ayuda que se materializó en una cantidad de dinero. Nadie como estos emigrados para conocer las dificultades por las que se atravesaba en Tetuán.

Otro de los acontecimientos que vino a turbar la inestable situación de la comunidad fue el acontecido en abril de 1893 en el que después de celebrada la Pascua y poco tiempo después, terminó el mes de Ramadán que se conmemoró con una gran fiesta en la que se hacían presentes al gobernador, fiesta a la que acudieron también algunos judíos. En la mismo tuvo lugar un desdichado accidente que acabó con la vida de un niño judío de diez años. Un caballo le enganchó y le arrojó al suelo produciéndose inmediatamente la muerte. Los padres pidieron justicia intentando ser recibidos por el gobernador. Pero era un día de fiesta y la multitud airada se lanzó contra los judíos que llegaron aterrados a su barrio. La matanza era inminente. La actuación del cónsul de España y de los militares de la delegación española consiguieron que el ataque no alcanzase mayores proporciones. Al fin la calma fue restablecida aunque la judería había sufrido

\footnotetext{
Teruel, Moreno, Pinto, León, Laredo, Ribas, de origen español, sellaron la iniciativa urbana del mejor organizado distrito del Tetuán antiguo. Las calles recibieron ios nombres de Kaisería, Prado, Las Griyas, Aniyi, del Huerco, de Maimón, de los Bañadores y de las distintas sinagogas que aparecian para el culto mosaico... Las sinagogas de esta juderia son 16 y reciben los nombre del la Meká o de la Fieunión, la Hebrá, el Estudio, la Pintada, la de Crudo, la de Bibas y Abudarán, la de Menahem Pariente, la de Maimón Benchetrit, la de Salomón e Isaac Nahón, y la de los rabinos Isaac Bengualid, Samuel, Israel, Vidal y Rubén. Ernesto JimENEz CABAllero, "La casa de un banquero». Raices, 18, primavera 1994, pág. 33: El barrio es una fortaleza con tres puertas sólo de relación al exterior: las calles son estrechas y sin recovecos como no sean estratégicos. Las casas muy altas, con enrejados ventanillos abiertos en las alturas ...".
}

Alegria Bendelac, Los Nuestros ... op. cit. pág. 330. Para más detalles ver págs. 330-333. 
múltiples heridos y los árabes habían entrado en las escuelas. Poco después los judíos fueron recibidos por el gobernador al que presentaron sus quejas. Pero éste les indicó que la muerte y las lamentaciones en un día de fiesta para los árabes era de mal augurio y les desagradaba y que además no les gustaba ver a los judíos en la medina.

En junio de 1894 murió el Sultán que viajaba desde el sur a Rabat, la capital. Su muerte fue muy sentida por los miembros de la comunidad judia a los que habia defendido con gran energía, aunque sus órdenes no siempre se habían seguido. Le sucedía un príncipe niño Muley Abd el Aziz. Eran tiempos difíciles desde el punto de vista político. Sin embargo se celebró una fiesta para conmemorar e! nuevo nombramiento. La comunidad presentó sus respetos al nuevo gobierno.

Una serie de acontecimientos desgraciados se van a suceder en estos finales de siglo. Un fuerte incendio se desató en la judería la noche del viernes al sábado del 15 de diciembre de 1894, incendio que se produjo en la antigua escuela, donde se acumulaban productos inflamables. Todos se volcaron en su extinción. Incluso el gobernador envió personal para controlar el incendio.

Pero no fue este el único de los problemas al final de siglo. El cólera, a pesar de las medidas de higiene, hizo nuevamente su aparición en septiembre de 1895 en la judería de Tetuán. La víspera de la fiesta penitencial de Yom Kippur registraba ya 30 muertos entre los musulmanes y 8 entre los judíos. El pánico se disparó en la comunidad. Constantemente se tomaban medidas para desinfectar. En la desinfección se usaban alquitrán, azufre, entre otros productos. El médico trabajaba día y noche. Los miembros de la Hebrah ${ }^{8}$ colaboraban en friccionar los cuerpos de los enfermos. La epidemia causaba grandes estragos. Varias familias huyeron a Xauen, Alcazarquivir e incluso Tánger. El médico, Dr. Berliowsky, escribía a la Alianza exponiendo lo duro de la situación: ... «el cólera ha entrado hace tres semanas con una fuerza inusitada. Cada día mueren diez o doce personas entre los israelitas y cuarenta o cincuenta entre los árabes...". Solicitaba un adjunto que le ayudara. Lo peor de todo era el miedo cerval que llegaba a extremos inauditos como el caso de la madre que preguntaba si podía coger a su hijito en brazos sin contaminarse, el marido que temía atender a su mujer ... El cólera era asiático, los medicamentos faltaban, y muchos de los instrumentos médicos no habían llegado. Poco a

8 Asociación, comunidad, cofradia. Se refiere a la 'Cofradía Santa' que se hacía cargo preferentemente de la preparación ritual de los muertos antes de ser enterrados. 
poco la epidemia empezó a ceder. Más de doscientas victimas habían muerto en las tres primeras semanas y doscientas cincuenta desde el principio. La Alianza envió un socorro que se distribuyó según las prioridades establecidas por el gran rabino.

Este último periodo del siglo XIX, supuso una difícil situación para la comunidad de Tetuán, a la par que un reto. La preparación recibida de las escuelas de la Alianza abría nuevas puertas a los judíos de Marruecos, aunque el siglo $x x$ comenzaba con nuevos problemas.

Así, la situación creada cuando en 1894 Mulay Abelaziz llega a Sultán con 14 años provocó un periodo de rivalidad en Marruecos desatado por Mulay Hafid, su hermano. Esta debilidad del reino desembocó en la mayor influencia de las potencias extranjeras que querían consolidar su dominio en Marruecos.

A finales de 1901 y principios de 1902 Tetuán sufrió del bandidaje de la cabila de Beni-Ider, que ya en 1890 se había sublevado contra la autoridad marroquí y atacaron y saquearon la judería lo que provocó la emigración a otras ciudades de Marruecos. Se conoce como la "Guerra de los Bnider» 9 . En esta ocasión atacaron a las caravanas que cruzaban el territorio marroquí. Un incidente acontecido en Tetuán con un miembro de la citada cabila motivó el desencadenamiento nuevamente de las hostilidades entre los Beni-Ider y Tetuán. Esto sucedía en marzo de 1903. La primera respuesta tuvo lugar cuando los miembros de esta cabila se apoderaron de una caravana de judíos que venía de Tánger. Los familiares acudieron al juez para que consiguiese la libertad de los prisioneros, lo que así sucedió. Pero Kadur ben el-Gazi, el juez, no cumplió su parte del trato, lo que desató las iras de los cabileños que se dispusieron a atacar la ciudad y ésta a defenderse. El incidente no hubiera llegado a mayores, ya que como hemos visto estas escaramuzas eran normales, sino fue porque la prensa española exageró la situación diciendo que la cabila de los Beni-ldder había destruido la judería matando a judíos y realizando un saqueo de la misma. El gobierno español envió un barco de guerra a Río Martín, para recoger a los judíos "supervivientes" a lo que éstos se negaron. Tetuán quiso hacer coalición con los de Anyera ${ }^{10}$ para defenderse pero la traición de Ed-Duas de esta cabila agravó la situación al resultar herido en un ataque de los tetuaníes.

\footnotetext{
9 Abd-ErRahim Yebbur Oddi, Una ojeada sobre la historia de Tetuán y las familias oriundas del "Andalus". Conferencia pronunciada el 17 de mayo de 1948 en el Centro de Estudios Marroquies por el prof. de árabe del mismo y Jefe de Interpretación de la Intervención territorial de $\mathrm{Ye}$ bala y del Municipio de Tetuán, Tetuán 1948 (datos de 1901-1903), pág. 17

10 Abd-ERrahim Yebbur Oddi, Una ojeada ...op. cit., pág. 3.
} 
Los de Anyera se sintieron ofendidos y se unieron a los de Bini-ldder para atacar a Tetuán. El Sultán envió un refuerzo de cien hombres al mando de su tío Mulay Arafa. Gracias a este refuerzo y al valor de los tetuaníes la ciudad consiguió salvarse. Sin embargo antes de retirarse incendiaron y destruyeron los huertos de la vega. La lucha continuó durante algún tiempo, pero los refuerzos venidos desde Tánger contribuyeron a que definitivamente se zanjase el problema.

Los judios se habían abierto a las ideas de Occidente gracias a la Alianza Israelita Universal. Por eso la conferencia de Algeciras en 1906 , preparó las zonas de influencia francesa y española ${ }^{11}$. Sin embargo poco o nada se había hecho para atraer a la población local marroqui y buscar su colaboración. Este vacío para hacer comprender lo que significaba la penetración pacífica de España vino a llenarse con las asociaciones hispanojudias del Norte de Marruecos ${ }^{12}$, entre ellas la de Tetuán ${ }^{13}$.

Es evidente que España después de la pérdida de su imperio colonial queria inhibirse de los problemas de África ${ }^{14}$, aunque no todos estaban de acuerdo en esta teoría ${ }^{15}$, pero se vio metida en un juego de alianzas en el que se vio obligada a participar. Es el periodo que conocemos como de el Protectorado.

11 Modesto Hernández Villaescusa, La cuestión de Marruecos y el conflicto de Melilia, Barcelona, 1893. Para ver los intereses de Francia, Inglaterra y España, págs. 156-172.

12 Isaac Guershon, "La Fundación de Asociaciones Hispano-Judias en Marruecos. Contrastes entre Tánger y Tetuán", Sephardic and Middle Eastern Jewries. History\&Culture in the Modern Era.Edited by Harvey E. Goldberg, Indiana, 1996, págs. 181-189: "La primera de estas Asociaciones la fundaron judíos y cristianos de Tánger el sábado 11 de mayo de 1912»... «En la creación de estas asociaciones cristiano-judias, y en las que se fcrmarán posteriormente en Ceuta, Larache y Alcazarquivir, intervinieron dos grupos distintos... El primero lo constituían un grupo de cristianos españoles filosemíticos, o mejor dicho filosefarditas, junto con numerosos judios españoles; el segundo era un grupo de judios marroquies»...«Durante los primeros años del siglo $x x$, el portavoz de la tendencia filosefardi fue el doctor Anyel Pulido ... Manuel Ortega ... editor de la Revista de la Raza...y también Ignacio Bauer y Alberto Bendelac... que fue durante un tiempo médico personal del rey Alfonso XIII...".

13 Isaac GúferSHON, "La Fundación de Asociaciones ...pág. 183:" El contexto de la Asociación Hispano-Judia era diferente en Tetuán, cuya comunidad era más tradicional y menos cosmopolita que la de Tánger. La élite rabínica gozaba de un nivel social más elevado y de más poder, y el porcentaje de quienes buscaban (y obtenian) la protección o la ciudadanía extranjera era menor que en Tánger, tal vez como reflejo del menor riúmero de hombres de negocio acomodados que en aquella ciudad".

14 José Fermín Bonmati Antón, Españoles en el Magreb, siglos xix y xx. Madrid, 1992, pág. 218: "No obstante España nunca prestaría atención a Marruecos más que como un campo de batalla y no constituiría sino un foco de preocupación".

15 Modesto Hernandez Villaescusa, La cuestión ... op. cit., pág. 169: "Nuestra vida nacional se halla tan intimamente unida a esta región atricaria, que más que un estado independiente, parece el Moghreb un girón de la patria española". 
El Protectorado español fue muy cuidadoso en la organización de la justicia. En lo que se refiere a los judíos aceptó las costumbres existentes perfeccionándolas y clarificándolas ${ }^{16}$. En Tetuán se estableció el Alto Tribunal Rabínico. El Protectorado fue una puerta abierta al mundo occidental. Las comunidades judías de Marruecos se vieron beneficiadas porque el Protectorado respetó sus peculiaridades y su forma de regirse ${ }^{17}$, pero modernizando sus estructuras para que estuviesen al nivel del resto del Protectorado.

También se había creado en Tetuán por Mosheh Hachuel un centro de enseñanza judía, llamado Yagdil Toráh, que intentaba una enseñanza con profesores y métodos más abiertos que los existentes hasta el momento ${ }^{18}$.

El Protectorado Español de Marruecos se había estableció el 27 de noviembre de 1912, cuando se fijaron las fronteras de los protectorados entre España y Francia. En esta fecha se firma en Fez, el tratado hispanofrancés ${ }^{19}$ por el que se reconoce la Zona del Protectorado español en el

16 José María Cordero Torres, Organización del ... op. cit.: «Los tribunales israelitas de caracter religioso estaban integrados por el Rabino mayor de la comunidad respectiva, como Juez ("Dayán") asesorado por dos "sofrina" o notarios". En 1924, por orden del gran visir, se constituyó en Tetuán un Alto Tribunal Rabínico integrado por tres miembos bajo la presidencia del Gran Rabino de Tetuán. pero fue el dahir de 20 de marzo de 1928 el que primero organizó de modo regular la jurisdicción israelita en la zona instituyendo tribunales rabínicos competentes en los asuntos del estatuto personal y sucesión de los israelitas marroquies, cuyos miembros se nombraron por dahir (art. $3 .^{\circ}$ ) y los secretarios por decreto visirial, pudiendo ejercer la enseñanza como circuncidores pero no albaceas, tutores 0 administradores de menores ni ejercer profesiones liberales, artes, oficios o industria (art. 5. ${ }^{\circ}$ ). Estos tribunales eran: Juzgados integrados por un rabino, un secretario en las principales ciudades (art. 3. $)$ y un Alto Tribunal en Tetuán para entender de las apelaciones contra los fallos de los anteriores, integrado por el Gran Rabino, dos consejeros elegidos entre los originarios de la zona y un Secretario, notario israelita teluaní; tendrian preferencia para actuar los rabinos sefardies de la zona debiendo todos conocer el castellano (art. 4."). Por decreto visirial de 21 de marzo de 1928 se establecieron Juzgados rabínicos en las regiones oriental (Nador), central (Tetuán), occidental (Larache). El título If del dahir de 20 de marzo de 1928 regula la organización del notariado israelita, que sólo podrán ejercer los nombrados por el Alto Tribunal Rabínico y registrados por un Secretario (art. 26 y 27 )

17 José María CoRdero Torres, Organización del Protectorado español en Marruecos, Madrid, 1942, 2 vols., págs. 248-250: "Un dahir de 31 de octubre de 1935 constituyó a las comunidades de Tetuán, Larache, Alcázar, Arcila, Xauen, Nador, Villa Sanjurjo y las que se formaren con todos los israelitas originarios marroquies, aunque hayan adquirido la nacionalidad extranjera, previo domicilio de un año en la localidad respectiva (art. $1 . \%$ ). Estas Comunidades tenían por ór gano una Junta, llamada consejo comunal, entre cuyos miembros figuraban un Presidente (Nasi), Vicepresidente (Segan-Nasi), suprimidos después, un Secretario (Mazkir), un Tesorero (Gisbar), un Administrador (Parnas) y un Contador o Interventor (Bodek-Hoxbon), más un número de vocales que oscilaban entre seis y quince miembros, reducidos posteriormente"

18 Notas manuscritas inéditas de José Benaim de la C.I. de Madrid.

19 E. Dupuy, Comment nous avons conquis le Maroc (Lalla-Marnia, Algésiras, Berlin, Fez, Madrid), 1845-1912, París, (1912). El capítulo IV La Conférance y el Acte de Algésiras, págs. 85 98 y el cap. Xll, sobre Le Protectorat. Les négociations franco-espagnoles. La misson de M. Reg nault. Le traité de 3 abril 1912. Les premières heures du Protectorat, págs. 279-316. 
que sensiblemente el dominio español es cada vez más pequeño ${ }^{20}$. El Sultán abdica en su otro hermano Mulay Yosef. En este mismo año el mellah de Fez es saqueado y los judíos tienen que refugiarse en el palacio del Residente General e incluso encerrarse para su protección en las jaulas de los leones. También en este año, España, con la aprobación de Francia y de otras potencias, se hizo fuerte en el Norte de Marruecos. La capital de este nuevo protectorado español fue Tetuán, que vivió unos años de prosperidad ${ }^{21}$.

En 1925 Tetuán estuvo a punto de caer en manos de Abd El Krim ${ }^{22}$ pero la defensa de la ciudad por parte de la guarnición, hizo fracasar la operación a pesar del asedio que duró varios meses. Primo de Rivera ${ }^{23}$, ocupó la cabila de Beni Urriaguel, de la familia del cabecilla marroquí y asistió a la entrada del nuevo jalifa ${ }^{24}$, regresando a Madrid y dejando de Alto Comisario al general Sanjurjo.

España al poner el pie en Marruecos trató de suplir las grandes deficiencias en sanidad, cultura y economía, volviendo a retomar las reformas que inició en 1860/62. Las dos primeras que acometió fueron inmediatas y la tercera se caracterizó por la construcción del ferrocarril: Ceuta-Tánger por Tetuán ${ }^{25}$ y la carretera de Ceuta-Tetuán-Tánger. Se construyeron dos

20 Juan Bta. VILAR «Los judios en el Protectorado español en Marruecos (1940-1956). Uriel MACIAS y Yolanda MORENO KOCH (coordinadores), Los judios en la España contemporánea:historia y visiones, 1898-1998. Actas del VIII Curso de Cultura Hispanojudia y Sefardi, celebrado en Toledo del 7 al 10 de septiembre de 1998 (en prensa): "El territorio adjudicado a España como Zona Norte de su Protectorado en el definitivo Convenio hispano-francés... consistia en 21.243, 07 $\mathrm{km} 2$, terreno en general abrupto, laberintico, pobre y superpoblado para sus cortos recursos, por calcársele una población de 45.000 habitantes, de los cuales 9.000 eran judíos...".

21 Henry MECHOULAM, Los judios ... op. cit. pág. 511.

22 José Caballero-Alcaraz, Historia ...op. cit., nus proporciona detalles sobre Abd-el Krim. Igualmente Manuel Gooeo, general, Marruecos. Las etapas de la pacificación.Madrid, 1932 para conocer la campaña contra el célebre personaje en 1926 y su suerte, págs. 247-324. El 10 de julio de 1926 se firmó un acuerdo franco-espanol de Madrid y en su punto 4 " "se resuelve que Francia le iriternará y le vigilara en la isla de Reunión».

23 José María MARin ARCE, "Primo de Rivera y la República del Rif durante los primeros años de la Dictadura. Negociaciones con Abd-El-Krim en junio de 1925". Actas / Congreso Internacional "El Estrecho de Gibraltar". Ceuta, 1890. Edición por Eduardo Ripoll Perelló y Manuel F. Ladero Quesada. Tomo V. Historia Contemporánea, Madrid, 1995, págs. 271-286.

24 Representante del Sultán en la Zona francesa y en la española.

25 José Garcia Cossio, Ceuta, historia gráfica, Ceuta 1984. Aparece una curiosa foto del ferrocarril entre Ceuta y Tetuán inaugurado el servicio el 10 de mayo de 1918 con la asistencia del infante D. Carlos de Borbón. Fue concesionario de la explotación su constructor D. José Arango. Joaquin RUIz PELAEZ, "Comunicación por via férrea entre Tetuán y Río Martín", (1809-1842)". Actas // Congreso Internacional "El Estrecho de Gibraltar". Ceuta, 1890. Edición por Eduardo Ripoll Perelló y Manuel F. Ladero Quesada. Tomo V. Historia Contemporánea, Madrid, 1995, págs. 141-146. 
nuevos puentes sobre el río Martín y se cultivaron las huertas de Tetuán que habían sido devastadas durante la ocupación y comenzó la urbanización y el Ensanche ${ }^{26}$ de la ciudad en la que se construyó un mercado y un dispensario ${ }^{27}$. Asimismo y aunque no existía un esquema urbano racional, ya que la mayor parte de los núcleos estaban emplazados en la linea de costa o en sus proximidades, Tetuán fue uno de los núcleos más poblados en 1935 con cerca de 50.000 habitantes y fue el centro de Protectorado español, incluyendo Ceuta y Melilla ${ }^{28}$.

En otras épocas hubo judíos viviendo en tribus, que permitían el asentamiento de unos pocos acogidos bajo la protección de algún notable. Llevaban una existencia humilde y se dedicaban al artesanado y a otras actividades como el comercio. El establecimiento del protectorado franco-español sobre Marruecos en 1912 facilitó que estos judíos pasasen a zonas de la costa atlántica y una parte importante a Tetuán, bajo la influencia de los judíos sefardíes.

En este ambiente las asociaciones sionistas se multiplicaron a pesar de la prohibición expresa formulada en 1924, lo que provocó quejas ente los grandes sionistas franceses como León Blum. En 1930 se celebró una conferencia sionista en Casablanca.

Pero la amenaza nazi se dejaba sentir con fuerza en Europa y sus ecos llegaban a Marruecos, por lo que los judíos formaron en todas las ciudades de Marruecos secciones de la Liga contra el antisemitismo (LICA), organizando socorros para los refugiados y haciendo gestos simbólicos como el ayuno después de la "Noche del Cristal».

Desde el comienzo de la guerra (1939-1945), los judíos que no formaban parte del Protectorado Español, vivieron una situación difícil. La derrota del general Nogu en 1940, representante del gobierno de Vichy trajo como consecuencia una serie de leyes restrictivas para los judíos: dificultades en la vida económica, en la enseñanza, en las profesiones liberales, etc. Los bienes judios fueron recensados en 1941 y los judíos que vivian en el barrio europeo fueron desplazados hacia el mellah. Las raciones alimenticias se redujeron a la mitad de las que recibía la población europea. Esta discriminación no encontró más que débiles ecos en la

26 ENCICLOPEDIA Universal ... op. cit., pág. 281. En 1928, según la citada Enciclopedia: El Ensanche o barrio europeo moderno, donde se halla el mercado, la Deelegación de Fomento, el Casino español, las escuelas, los principales hoteles y los servicios de Correos y Telégrafos.

27 Ramón Salas Larrazabal, El Protectorado ... op. cit. pág. 138.

28 José Fermín Bonmati Antón, Españoles en el Magreb, siglos xix y xx, Madrid, 1992 , pág. 246 
población musulmana y en el Sultán Muhanmad ben Yusef, más tarde Mohamed $V$, que manifestó su hostilidad a esta persecución.

Después de la guerra civil, España continuó la tarea emprendida antes del conflicto, tanto en el campo económico como en el social o cultural.

En 1948, nació el estado de Israel.

Este es el ambiente en el que vivió R. Yishaq bar Vidal Ha-Serfaty y en el que fue recogiendo los datos de los judíos que circuncidaba en el Libro Registo de Circuncisiories.

\section{EL LIBRO REGISTRO DE CIRCUNCISIONES}

El Libro Registro de Circuncisiones ${ }^{29}$ de R. Yishaq bar Vidal Ha-Serfaty se incorporó a las colecciones del Museo Sefardi de Toledo como depósito para la inauguración del mismo el 13 de junio de 1971. En 1982, pasó a formar parte de la colección permanente del Museo.

Es de gran interés para el conocimiento de la comunidad sefardí de Tetuán entre los años 1880 y 1940 por los datos que en el mismo se proporcionan. Está integrado por dos cuadernos, el primero de los cuales contiene 638 registros, que abarcan los años 1880-1889. El segundo, más completo, recoge estos 638 circuncidados y continua hasta el registro 2725 en el mes de Ab (agosto) de 1940.

\section{A) El autor}

R. Yishaq bar Vidal Ha-Serfaty, (1866-1941), era hijo de R. Vidal, shekh de la comunidad de Tetuán y de Sarah, hija de Yaaqob Obadiah. Con su padre debió prepararse para el rabinato por la temprana edad en que empezó a ejercer de mohel ${ }^{30}, 15$ años aproximadamente. Sus antepasados, según obra en un documento del Museo Sefardí, se remontan a Rabenu Tam ${ }^{31}$. Tuvo cuatro hermanos: Shalom, muerto en 1924 casado con Mesodi, Yaaqob, que casó con Piedad y fue shekh ${ }^{32}$ de la Hevrá Kadishah y

29 En adelante LRC.

30 El que realiza la circuncisión.

31 Yaaqob ben Meir Tam, tosafista (comentarista del Talmud) nacido en 1100 en Ramerupt y muerto en Troyes, Francia en 1171. Se le ha apodado Rabenu Tam (nuestro maesto, el perfecto o el sencillo) por la santidad de su vida y por considerarárseie el más grande entre las autoridades rabínicas de su tiempo. Enciclopedia Judaica Castellana, vol. X, Méjico, 1951, págs. 168-169.

32 Jefe, director. 
tuvo tres hijas, Eliyahu casado con la hija de Yishaq Obadiah que tuvo cinco hijos que aparecen en el LRC circuncidados por su tío y una hermana: Sara casada con Yiaq Garzón y madre de Elihú, y citada en el LRC (foto n. ${ }^{\circ}$ ).

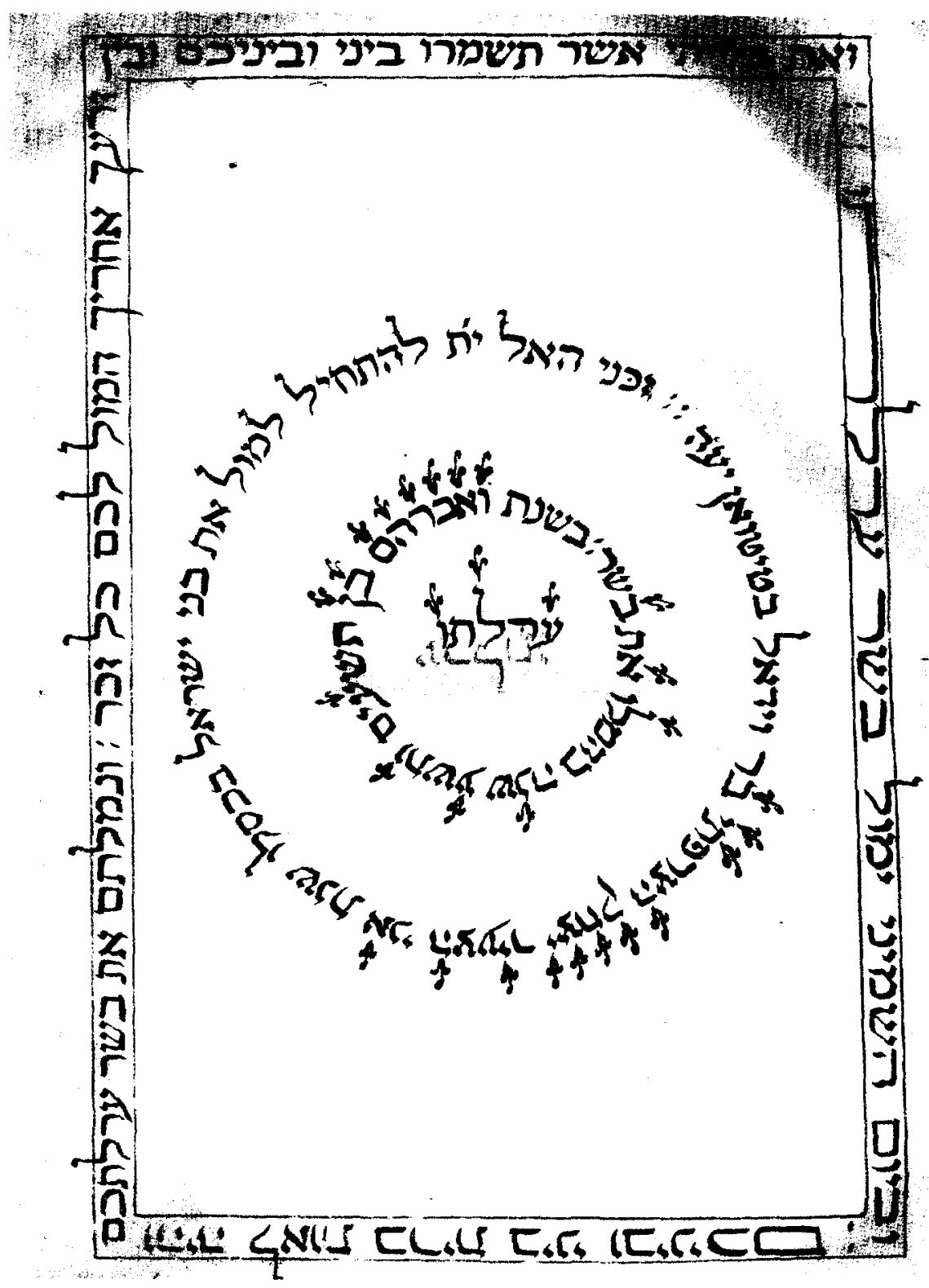


Casado R. Yishaq con Rahel Azerad en Tetuán, (foto $n .^{\circ}$ 2) el 18 de Siwán del 5641, 1881, no tuvo descendencia y su sobrina, Rahel Ha-Serfaty, segunda hija de Yaaqob y de Piedad, que hubiera tenido que llevar el nombre de la madre de su madre, recibió el nombre de su tía Rahel, "para que ella fuera como la nieta que habría así nombrada de haber tenido R. Yishaq hijos" ${ }^{33}$. Fue shekh de la judería. Existe un impreso de 1941 en el Museo Sefardi que tiene como protagonista a "Dn. Issac V. Aserfat, chekh de la judería ${ }^{34}$. Evidentemente, se trata de nuestro protagonista, que en la judería

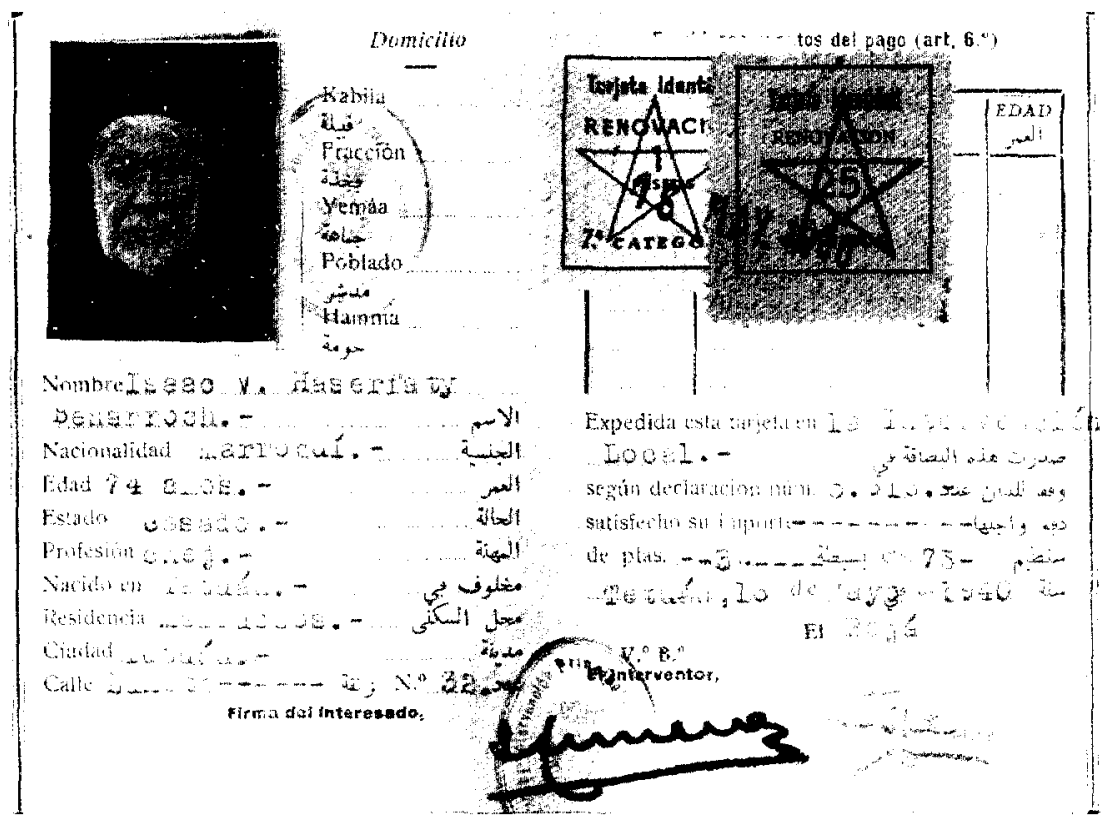

33 Datos proporcionados por la propia Rael Ha-Ha-erfaty, ya fallecida, descanse en el Edén y por un miembro de su familia. Abraham I.LAREDO, Les noms des juits du Maroc. Essai d'onomastique judeo-marocaine, Madrid, 1978, pág. 31: «Le choix des noms ne se fait pas au hasard; il obéit, en général, à une regle traditionellement respectée, qui comporte l'ordre suivant: on donne au premier né le nom du grand-père ou de la grand'mère paternels, au deuxième celui du grandpère ou de la grand'mère maternels; au troisième celui de l'oncle ou de la tante ainés paternels, au quatrième celui de l'oncle ou de la tante ainés maternels et ainsi de suite a tour de rôle entre la famille du mari et celle de la femme, par ordre de degré de parenté et d'âget.

34 (Encabezado por una estrella de seis puntas que lleva inscrita en su interior una de cinco, lleva a mano derecha una leyenda en dos lineas: Saludo a Franco ¡iArriba España!!).

Inmediatamente debajo: INTERVENCIÓN REGIONAL DE LA YEBALA.

Negociado 1. (subrayado).

(En letra gótica): Don Francisco Trujillo Machacćn, Comandante de Infanteria, / Interventor Regional de Yebala. 
de Tetuán tenía una calle con su nombre ${ }^{35}$. Esta condecoración no hace más que reconocer los méritos de R.Yishaq bar Vidal Ha-Serfaty, quien fue uno de los miembros de la Asociación Hispanojudía de Tetuán que colaboró en el buen entendimiento entre los españoles del Protectorado y los judios tetuanies ${ }^{36}$.

El Libro Registro de Circuncisiones se cierra con el individuo $\mathrm{n} \cdot{ }^{\circ} 2725$ que habia nacido el 14 de agosto (10 'Ab) y fue circuncidado el 21 de este mismo mes (17 de 'Ab). Desde el registro 2714, particularmente en lo que se refiere a la filiación y oficio parece notarse una segunda mano o la mano temblorosa de un anciano ya que los caracteres están realizados menos cuidadosamente. Según nos indicaron miembros de su familia estaba enterrado en Tetuán. La fotografía de su tumba proporcionada por Rubén Benaim de Tánger nos ha confirmado el lugar de enterramiento y la fecha de su fallecimiento, el año1941.

El $\operatorname{siman}^{37}$, que se recita en el primer año de fallecimiento y en el aniversario del mismo nos ha confirmado los datos de R.Yishaq pues las iniciales de cada verso van formando su nombre y el de su madre Sara: Yishaq bar Sarah". A continuación del nombre de su madre la expresión: "Satán sea maldito". En los versos finales están las oraciones comunes a todos los simanim" ${ }^{38}$. La familia de R. Yishaq bar Vidal Ha-Serfaty ha conservado este simán que la Hevrá Qadishah entrega a los familiares del fallecido.

Su memoria es venerada en la comunidad judía de origen marroquí, incluso hemos podido consultar dos bendiciones, escritas de su puño y

CERTIFICO: que, según consta en esta Intervención Regional / de mi cargo, y por el Excmo. Sr. Ministro del Ejército, le ha sido / concedida la MEDALLA DE LA CAMPAÑA con distintivo / RETAGUARDIA a (cumplimentado a mano) DN. ISSAC V. ASERFAT. CHEJ DE LA JUDERÍA (adorno) / Y para que conste y pueda el interesado acreditarlo, expido el presente en Tetuán a veinti cuatro de abril de mil novecientos cuarenta y uno.

(Firmado por el Comandante de Infanteria Francisco Trujillo).

35 Manuel Alvar, Endechas judeo-españolas. Edición refundida y aumentada con notación de melodias tradicionales por Maria Teresa Rubiato. Madrid, 1969. Lám. entre págs. 120 y 121.

36 Isaac GUERSHON, «La Fundación de Asociaciones Hispano-Judías en Marruecos. Contras tes entre Tánger y Tetuán". Sephardic and Middle Eastern Jewries. History \& Culture in the Modern Era.Edited by Harvey E. Goldberg. Indiana, 1996 "Al comité de la asociación pertenecian miembros de todas las familias de notables de la comunidad judia de Tetuán, y muchos de sus di rigentes eran funcionarios municipales. Además de Garzón y Toledano, fueron elegidos José Cazes como secretario general, Abraham Coriat tesorero, e Isaac Serfati, que era sheikh de la judería (encargado del orden público en el barrio judio). vicetesorero...", pág. 185

33. 'Señal o fómula de identificación del individuo'. A. Isaac LAREDO. Les noms des juifs du Maroc. Essai d'onomastique judéo-marocaine. Madrid, 1978, págs. 47-48.

38 A.Isaac LAREDO, Les noms des juifs .. op. cit..: «la derniere partie du Siman constitue une sorte de conjuration des forces d'obstruction» entre el mundo visible e invisible, pág. 47. 
letra ${ }^{39}$, que se colocan a los recién nacidos para protegerles de todo mal, según consta escrito por Yaaqob hermano de R. Yshaq.

\section{B) Descripción}

Las medidas de ambos libros son iguales: $25 \mathrm{~cm}$. de longitud y $30 \mathrm{~cm}$. de anchura. El segundo, básicamente por contener más datos, ha sido objeto de este trabajo, consultando en el primero también los 638 registros inscritos para agregar los datos proporcionados en éste que no aparecen en el segundo. Se tratan propiamente de dos cuadernos con las páginas numeradas, y renglones, como si debieran utilizarse para registros contables, y donde aparecen manuscritos los nombres de los circuncidados escritos con tinta negra. Debido a la mala calidad del papel, a veces la tinta cala el reverso de la hoja y dificulta en ocasiones la lectura de los registros.

Tienen ambos Libros la portada manuscrita a tinta negra con una serie de versículos bíblicos en hebreo alusivos al hecho de la circuncisión y dispuestos artísticamente dando la vuelta a toda la hoja, siguiendo la costumbre de las páginas tapiz de los manuscritos de la Edad Media. Estos versículos proporcionan una serie de datos sobre el lugar de procedencia de los circuncidados, el año en que se inicia el LPC y el nombre del mohel, Yishaq bar Vidal Ha-Serfaty.

Gen 17, 10-11.

10. He aqui mi pacto, entre mi y vosotros, que habéis de guardar, así como tu descendencia después de ti: serán circuncidados todos vuestros varones 11 Os circuncidaréis, pues la carne del prepucio, lo cual servirá de señal entre mí y vosotros.

Lev12, 3.

Al octavo día se circuncidará al niño.

Asimismo aparecen dos círculos concéntricos con inscripción hebrea y adornos flordelisados sobre algunas letras que dan la fecha del inicio del Libro Registro de Circuncisiones: 1881

Círculo más externo:

Purificame ¡On Señor!, bendito seas, para circuncidar a los hijos de Israel, en kislev, en el año: yo el joven Yishaq Ha Serfaty bar Vidal, en Tetuán ¡Dios la consolide!

\footnotetext{
39 Las dos contienen el mismo texto. Una comienza por: "Pues tu eres Adonay mi refugio", y la segunda "Levanto Adonay mi rostro hacia tí", a las que siguen cinco palabras hebreas, colocadas simétricamente, que hacen alusión a distintos pasajes bíblicos.
} 
En el círculo más interno, Gen 17, 24:

Tenía Abraham noventa y nueve años cuando se circuncidó la carne de

En el centro (continuando el versículo anterior):

su prepucio

El estudio del Libro Registro de Circuncisiones nos ha hecho percibir el trabajo personalizado del rabino Ha-Serfaty, lo que le ha llevado a cometer errores e incluso entre los registros que aparecen en los dos Libros hay diferencias de oficios entre el primero y el segundo. Asi por ejemplo hay dos casos con del mismo número de registro y distintos apellidos. También hay errores en las fechas. A veces coloca parches para corregir errores, también hace tachones y utiliza a veces distinta tinta o lápiz para rellenar blancos que ha dejado, al desconocer una información y tener posteriormente datos de la misma. A veces aparecen anotaciones de mano diferente en letra cursiva donde leemos: "arelado por mi Yaacob Haserfaty porque al parecer se equivocó Yishaq mi hermano y en vez de poner Yishaq puso Masod".

Otras veces nos proporciona una serie de precisiones sobre los días festivos en que se realiza la circuncisión: «2. día de Pesah» (2..$^{\circ}$ día de la fiesta de la Pascua), «1. y $8 .^{\circ}$ de Hanukkah", (1er y $8 .^{\circ}$, último día de la Fiesta de las Luces), en la fecha de nacimiento: "Rosh ha-Hodesh" («primero de mes»), etc.

En segundo lugar, hay un número de circuncidados que detrás del nombre y apellido, llevan la expresión "le tomé yo" en un porcentaje de un $1 \%$, correspondiente a 22 individuos circuncidados. Creemos que esta expresión puede hacer referencia por un lado a una voluntariedad del rabino para realizar la circuncisión e igualmente también puede suponer un «padrinazgo" con el significado espiritual que ello conlleva ${ }^{40}$ (gráfico 1 ).

También aparece la expresión «el nombre de su padre». Dado que al circuncidado se le pone el nombre del abuelo y nunca el nombre de su padre si éste está vivo, he de colegir, cuando no lo especifica, que el padre del circuncidado ha fallecido. Son 22 los casos en los que aparece esta indicación ${ }^{41}$ (gráfico 2).

40 Consultado José Benaim de la Comunidad Israelita de Madrid, nacido en Tetuán, en el mes de marzo de este año nos ha explicado que esta expresión quiere indicar que el rabino que los circuncida también los apadrina. Esto solía suceder cuando se trataba de "familias muy humildes".

Para la elaboración de nuestro trabajo nos fueron de gran utilidad nuestras entrevistas tanto con el citado José Benaim como la de Isaac Benatar, también de la Comunidad y asimismo también nacido en Tetuán.

41 Ver nota 9. 


\section{Gráfico 1}

\begin{tabular}{|c|c|}
\hline APPELL_NOM & NOMBRE \\
\hline Azulay & Isaac, «le tomé yo" \\
\hline Hachuel & Salomón «le tomé yo" \\
\hline Chocrón & Salomón «le tomé yo" \\
\hline Israel & Abraham "le tomé yo" \\
\hline Ben Dayán & José "le tomé yo" \\
\hline Garzón & Semtob, «le tomé yo» \\
\hline Azerad & Selomó, "le tomé yo" \\
\hline Ben Simhon & Yoseh, "le tomé yo" \\
\hline Ha-Serfaty & Vidal, «le tomé yo» \\
\hline Israel & Abraham, "le tomé yo» \\
\hline Hachuel & Mosé, «le tomé yo en Ceuta" \\
\hline Ben Zaquén & Abraham, "le tomé yo» \\
\hline Enaqab & Yaacob, "le tomé yo" \\
\hline Pinhas (nombre o apellido) & Pinhas, "le tomé yo" \\
\hline Israel & Abraham, "le tomé yo" \\
\hline Israel & Abraham, "le tomé yo" \\
\hline Esebach & Mosé, «le tomé yo» \\
\hline Ben Zaquén & Amram Saadía "le tomé yo" \\
\hline Israel & Yishad "le tomé yo" \\
\hline Vuahnes & Yishad "le tomé yo" \\
\hline Ben Zaquén & Yishad Saadia "le tomé yo" \\
\hline Ha Levi & Yaacob «le tomé yo» \\
\hline $\begin{array}{l}\text { Total } \\
2725\end{array}$ & $\begin{array}{c}\text { Sin "le tomé yo" } \\
2703\end{array}$ \\
\hline
\end{tabular}

Con "le teme vo" $\quad \square$ sin "le ume vo"

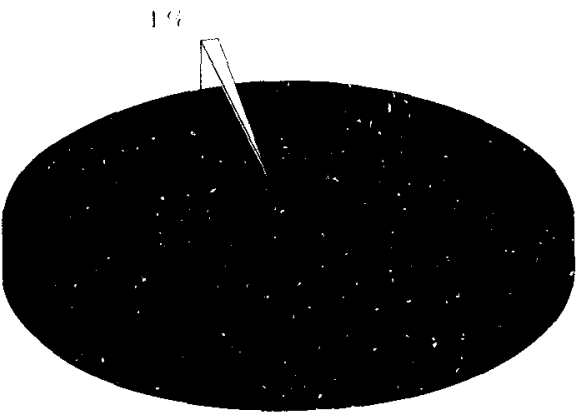

(9) 4 
La comunidad judia de Tetuán (1881-1940). Datos sociológicos en el libro...

\section{Gráfico 2}

\begin{tabular}{|c|c|}
\hline APELLIDOS & NOMBRE \\
\hline Albo & Yaacob, «le nombre de su padre» \\
\hline Attiah & Isaac, «le nombre de su padre» \\
\hline Abecasis & Isaac, «le nombre de su padre» \\
\hline Brujel & Jacob, «le nombre de su padre» \\
\hline Uziel & Yehudá, "le nombre de su padre» \\
\hline Bentata & Yishad, "le nombre de su padre» \\
\hline Nahón & Abraham, "le nombre de su padre" \\
\hline Bono & David, "le nombre de su padre" \\
\hline Almosnino & Abraham, "le nombre de su padre" \\
\hline Poinquinos & Yamin, "le nombre de su padre» \\
\hline Benaseraf & Yosef, "le nombre de su padre" \\
\hline Ben Chimol & Aquiba, "le nombre de su padre" \\
\hline Albo & Yaacob, "le nombre de su padre» \\
\hline Enqam & Semuel, "le nombre de su padre" \\
\hline Vuahnón & Yishaq, «le nombre de su padre» \\
\hline Truchman & Eliahum "le nombre de su padre" \\
\hline Benatar & Eliahu, "le nombre de su padre" \\
\hline Ha Levi & Yishaq, "le nombre de su padre" \\
\hline Almosnino & Semuel, "le nombre de su padre» \\
\hline Esayag & Abraham, "le nombre de su padre" \\
\hline Ben Tolila & Rafael, «le nombre de su padre» \\
\hline Azerad & Aquiba, "le nombre de su padre" \\
\hline Total & Con el nombre de su padre \\
\hline 2725 & 2703 \\
\hline
\end{tabular}

Con el nombre de su padre $\quad \square$ Sin el nombre de su padre

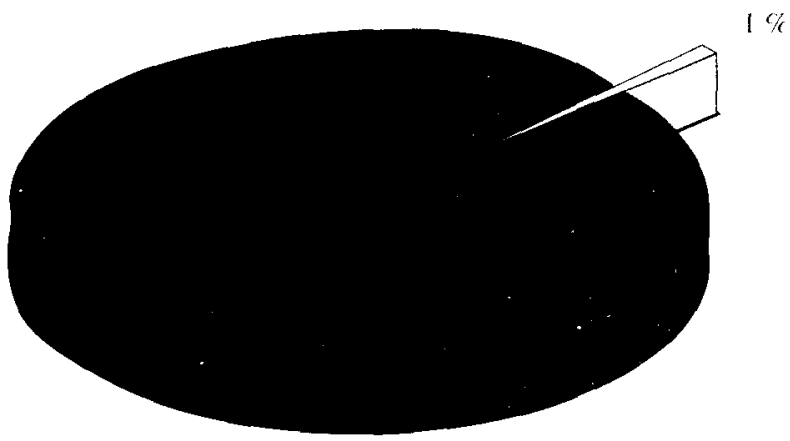

$99 \%$ 
En último lugar y en cuatro registros, Ilama nuestra atención que detrás del nombre del circuncidado aparece la palabra hebrea mi dayyán. Creemos que alude a la persona que entendia de asuntos jurídicos en el equipo de la sinagoga Bibas que él regentaba. No creemos que sea una corrupción de la palabra minyán, quorum. También se nos presentarian serias dudas en este último caso. ¿Es que tal vez tuvo dificultades para tener este quorum en estas cuatro circuncisiones? No parece existir ninguna causa que lo justifique (gráfico 3 ).

\section{Gráfico 3}

\begin{tabular}{ll}
\hline \multicolumn{1}{c}{ APELLIDOS } & NOMBRE \\
\hline $\begin{array}{l}\text { Esayag } \\
\text { Tobelem } \\
\text { Ben Dayan } \\
\text { Ben Baruj }\end{array}$ & $\begin{array}{l}\text { Eliahu, «midyyán» } \\
\text { Yaacob, «midyyán» } \\
\text { Con "midyyán» } \\
4\end{array}$ \\
\hline
\end{tabular}

2721

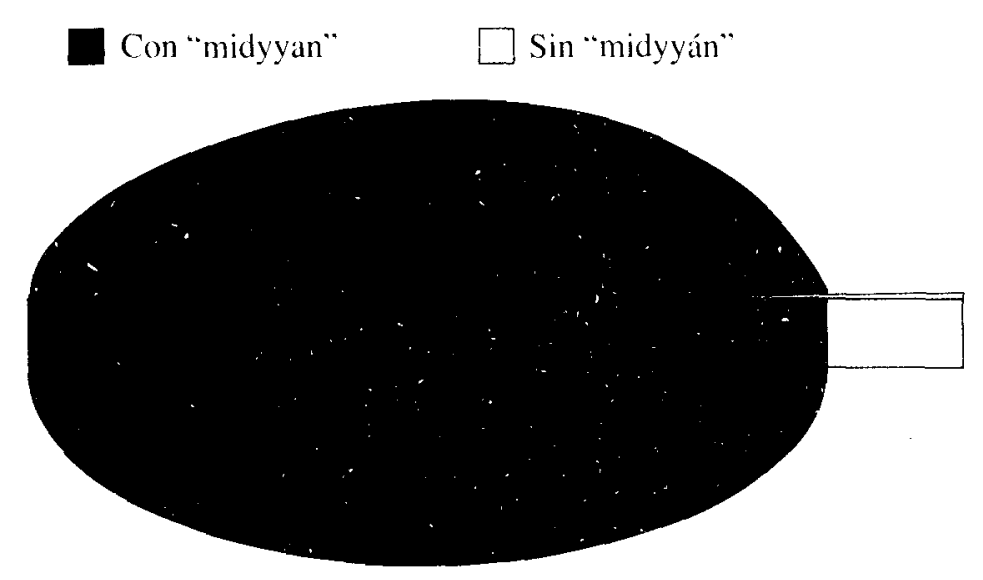




\section{C) Contenido}

El Libro Registro de Circuncisiones aparece dividido por años hebreos, aunque también incluye el comienzo del año del calendario juliano. Los registros aparecen colocados ocupando dos páginas consecutivas como si tuviera forma apaisada. En la primera de las páginas los siguientes epígrafes:

- $\mathrm{N}{ }^{\circ}$ registro.

- Fecha nacimiento.

- Fecha circuncisión.

- Nombre y apellido del circuncidado (letra cuadrada).

en la segunda página:

- Padres (filiación): padre casi siempre.

- Oficio de padre.

- Nombre de la madre y en su defecto filiación (1927).

- Observaciones: escasas:»fallecido», “padre cristiano».

Es evidente interés el interés de los datos que el libro contiene ya que es equivalente a un registro civil. En ocasiones y en épocas de revueltas los judios no acudían a inscribirse oficialmente y sólo existía la constancia de lo que el rabino reflejaba en su "cuaderno".

\section{ANÁLISIS SOCIOLÓGICO}

El análisis de los datos del Libro Registro de Circuncisiones, indica que el año en que se produjeron un mayor número de circuncisiones fue en de 1901, con 76. Le siguen en importancia el de 1926 con 64 y 1909 con 63. Salvo el año de 1888 en que fueron circuncidados, 58 individuos, las cifras más altas de circuncidados corresponde a distintos años del siglo $x \times(1901,1926,1909,1932,1927,1928,1925,1931,1923)$ en orden decreciente. Estos años coinciden con una mayor estabilidad política coincidente en gran parte con el Protectorado Español, trajo aparejado un mayor equilibrio económico y unas mejores condiciones de higiene y salubridad, facilidades para la escolarización, saneamiento de las viviendas, disminución de las epidemias como consecuencia de las medidas anteriormente citadas, fueron factores importantes para que hubiera un mayor número de nacimientos y consecuentemente de circuncisiones. Por lo que se refiere al año de 1888, no hay una explicación basada en un hecho político, económico o social, pero la comunidad de Tetuán vivía 
en este momento un periodo de paz, la escuela de la AlU funcionaba para niños y niñas, había desaparecido el bandidaje y por otra parte las noticias que llegaban de los emigrados, eran positivas. Podemos pensar que en la comunidad existía un clima de esperanza que se tradujo en un mayor número de nacimientos. (gráfico 5).

\section{Gráfico 5}

\begin{tabular}{cc}
\hline AÑO CIRCUNCISIÓN & N. de Circuncidados \\
\hline 1901 & 76 \\
1926 & 64 \\
1909 & 63 \\
1932 & 62 \\
1927 & 61 \\
1928 & 61 \\
1925 & 60 \\
1931 & 60 \\
1888 & 58 \\
1923 & 58 \\
\hline
\end{tabular}

ATOS Mis CIRCLVCLADOS

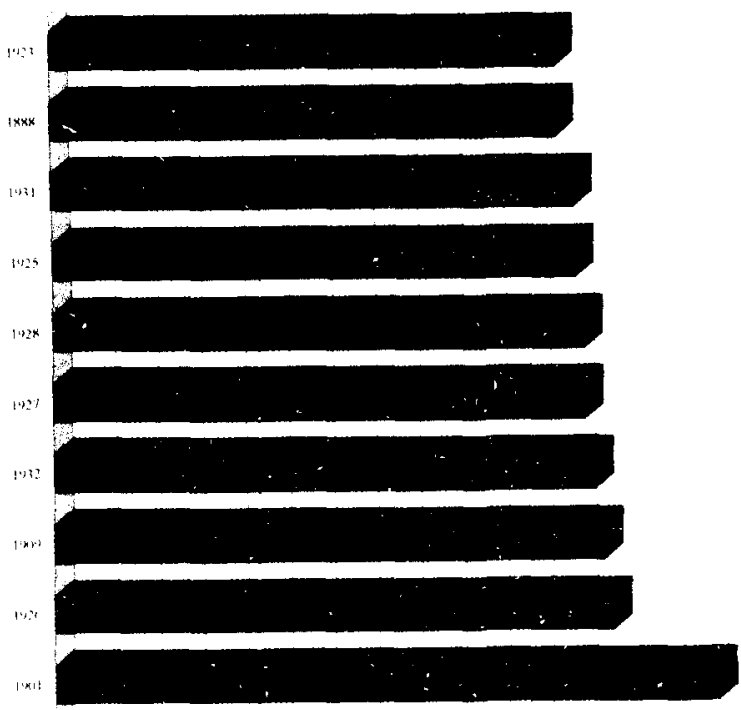


Por lo que se refiere a los años de menor número están localizados en dos periodos claramente diferenciados. Son los años de: 1881, 1882 , 1883, 1884, 1885, 1886, 1887, 1916, 1917, 1918. 1920 (gráfico 6).

\section{Gráfico 6}

\begin{tabular}{cc}
\hline AÑO CIRCUNCISIÓN & N. de Circuncidados \\
\hline 1880 & 1 \\
1881 & 3 \\
1882 & 6 \\
1884 & 8 \\
1883 & 10 \\
1885 & 10 \\
1940 & 17 \\
1886 & 22 \\
1920 & 26 \\
1918 & 27 \\
\hline
\end{tabular}

AÑOS MENOS CIRCUNCIDADOS

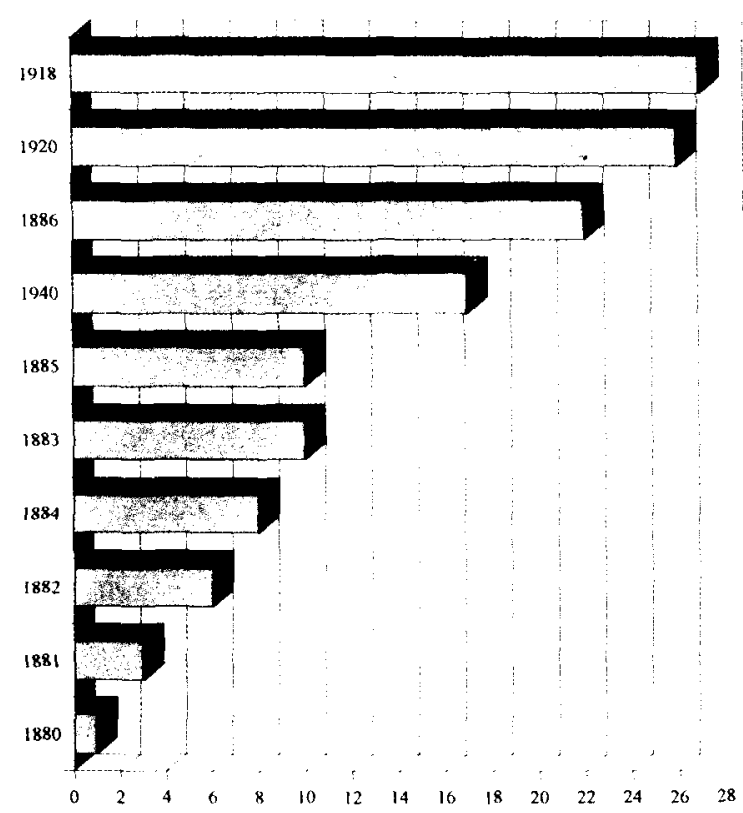


Los primeros años 1881-1886 coinciden con el inicio del Libro de Registro y con el de la actividad como rabino de R. Yishaq bar Vidal Ha-erfaty, y es un periodo en el que la comunidad se recupera de asaltos a las comunidades judías en el Norte de África y otros problemas graves incluida la pobreza. Así en 1884 hubo en la comunidad una epidemia de varicela. En 1885 R. Yosef “Eimaleh murió a bastonazos en Denmat». La situación política tampoco era muy favorable.

Otro periodo de baja son los años 1916, 1917, 1919, 1920, años de grandes avatares políticos en Europa coincidentes con la 1. a Guerra Mundial que de alguna manera encontraban un fuerte eco a través de las escuelas de la Alianza Israelita Universal y de los consulados de potencias extranjeras existentes en Tetuán.

Por otra parte, una vez extractados los registros del Libro Registro de Circuncisiones, su estudio ha dado como resultado la repetición de una serie de datos en los circuncisos. El nombre del padre y su oficio, el nombre de la madre y en su defecto la filiación de la misma y algún otro detalle específico como un apodo, una procedencia, un título, me han llevado a conocer que en general en la comunidad de Tetuán existió una fuerte natalidad. Sin embargo es necesario hacer la precisión de que me estoy refiriendo sólo al nacimiento de varones por razones obvias, por lo que es evidente que el análisis de los datos es relativo.

Del estudio de estos datos hemos llegado a los siguientes resultados:

\begin{tabular}{|c|c|c|c|}
\hline 4 & familias, & tuvieron & 8 \\
\hline 8 & familias, & tuvieron & 7 \\
\hline 31 & familias, & tuvieron & 6 \\
\hline 55 & familias, & tuvieron & 5 \\
\hline 96 & familias, & tuvieron & 4 \\
\hline 66 & familias, & tuvieron & 3 \\
\hline
\end{tabular}

Es decir que un total de 614 familias de la comunidad tuvieron un total de 1889 hijos. Dado que el número de circuncidados es de 2725, 725 son hijos únicos, o al menos me ha sido imposible encontrar datos coincidentes que permitan saber, si cada uno de ellos era en verdad hijo único (según el LRC, sí) o podian pertenecer varios a la misma familia, o tal vez tuvieron hermanos que murieron antes de ser circuncidados. A veces, como en el caso de dos hermanos de R. Yishaq Vidal Ha-Serfaty que portan el mismo nombre, me lleva a concluir que uno cie ellos murió por lo que otro hermano tomó el mismo nombre. 
También en el LRC aparecen 15 parejas de mellizos con sus nombres que reseña el propio R. Yishaq Vidal Ha-Serfaty (gráfico 4).

También el LRC nos permite saber algunos detalles sobre la mujer en este periodo. Hasta el año 1927, sólo en contadas ocasiones aparece el nombre de la madre y solamente la conocemos por ser "hija de", "esposa de» o "madre de». A partir de este año y hasta 1940, sin que haya una razón específica que lo justifique, aparece sistemáticamente el nombre de la madre. A veces en los primeros registros, aparece el nombre y el apellido

\section{Gráfico 4}

\begin{tabular}{|c|c|}
\hline APELLIDOS & NOMBRE \\
\hline Pinto & Mojlof «mellizo con reg. $515 »$ \\
\hline Pinto & Isaac, «mellizo con reg. $514 »$ \\
\hline Azerad & Yamin, "mellizo con reg. 659 " \\
\hline Azerad & Yosef, "mellizo con reg. 658 " \\
\hline Serulla & Yishaq, “mellizo con reg. 746 " \\
\hline Serulla & Yaacob, "mellizo con reg. 745 " \\
\hline Enquam & Eliahu, “mellizo con reg. 1216 " \\
\hline Enquam & Mordejay, “mellizo con reg. $1215 »$ \\
\hline Ben Hamu & Yosef, "mellizo con reg. $1355 »$ \\
\hline Ben Hamu & Simeón, "mellizo con reg. 1354 " \\
\hline Ediray & Yishaq, "mellizo con reg. 1431" \\
\hline Ediray & Selomó, «mellizo con reg. 1430 " \\
\hline Pinto & David, «mellizo con reg. $1467 »$ \\
\hline Pinto & Simón, «mellizo con reg. $1466 »$ \\
\hline Obadia & Mosé, «mellizo con reg. 1500 » \\
\hline Obadia & Yona, "mellizo con reg. $1499 "$ \\
\hline Benarós & Yishaq, «mellizo con reg. $1903 »$ \\
\hline Benarós & Mosé, "mellizo con reg. 1902" \\
\hline Garzón & Yishaq, "mellizo con reg. $2049 "$ \\
\hline Garzón & Pinhas Eliahu, "mellizo con reg. 2048" \\
\hline Ha Cohén & Yishaq, "mellizo con reg. 2446 " \\
\hline Ha Cohén & Amram, "mellizo con reg. 2445 " \\
\hline Bentata & Yehudá, "mellizo con reg. 2518» \\
\hline Bentata & Gabriel, "mellizo con reg. 2517 " \\
\hline Ben Halal & Abraham, «mellizo con reg. $2523 »$ \\
\hline Ben Halal & Samuel, «mellizo con reg. 2522 " \\
\hline Ha Cohén & Yosef, "mellizo con reg. $2577 "$ \\
\hline Ha Cohén & Yaacob, “mellizo con reg. 2576» \\
\hline Tamsot & Eas, "mellizo con reg. 2614» \\
\hline Tamsot & Hayim, “mellizo con reg. 2613 " \\
\hline Mellizc & Total \\
\hline 30 & 2725 \\
\hline
\end{tabular}




\section{MELLIZOS}

$\square$ NO MELLIZOS

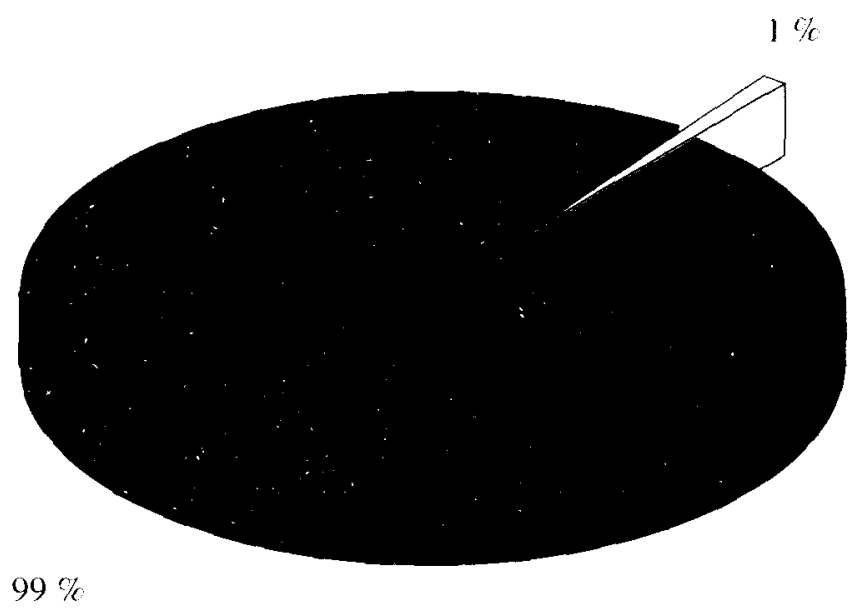

para especificar después "qazadah qon qristiano», "Zahra, mi hermanah». Tampoco cita el nombre de la madre, en el caso del circuncidado que es hijo de la "ikhah de Yehudah ben Shimol, de lah que "erah mi quniadah", aunque, lógicamente debe conocerlo. Hay registros donde nos hace especificaciones como: "Rahelitah 'Enqam, qriadah". Suponemos, que es madre soltera porque no aparece el nombre del padre del circuncidado, ni tampoco el del padre de «Rahelitah», aunque si su apellido. Igualmente ocurre con, "Yaqut de Fato, "ikhah de Frehah sirbientah", donde no está el nombre del padre del circuncidado ni del padre de Yaqut, aunque sí su apellido Ben Dayyán. O en el caso de: "Chohar, sirbientah", aunque en este caso aparece la filiación completa de su padre, Yosef Ben olilah. Sin embargo la palabra hebrea betulah «virgen» y por extensión "madre soltera», no aparece hasta el año 1896 referido a una joven, hija de 'Abraham Garshón, conocida por el sobrenombre de «la Moshqah». No conocemos su nombre aunque si su apodo. El nombre del padre del circuncidado que aparece entre paréntesis es Saúl. Tenemos 16 casos en los que aparece la palabra batulah "madre soltera" y dos en los que por la falta de datos hemos de concluir que también los son.

A veces nos da detalles. lo cual no deja de sorprendernos por la precisión: «Estinoah, lah de Boninah"; o "Rahel, lah de "esquelah». Suponemos que se está refiriendo a la profesora de la AIU, Fiahel Behar. Otras veces es 
una precisión de tipo familiar, "Oro, de mi tio", "Chohar, de 'er' riqah", ¿se refiere a que su hermana poseía bienes de fortuna o a que era Riqah de nombre? ${ }^{42}$. "Perlah Hayyón», donde no sólo nos da el nombre de la madre, sino que además proporciona el apellido, aunque no el nombre de su padre, "Simitah, lah de Piri".

A veces recoge un diminutivo de la madre como si tuviera conocimiento o amistad con la familia de la misma "Masuditah", "'Oraguenitah", "Dinitah", “Finitah», "Qoti (Yaqut)", etc. En otra ocasión al dar el nombre de la madre, Rahel, hace una aclaración»dice Yaaqob que es «ikhah de Yishaq Benzaquén, rifi». ¿Se está refiriendo a una aclaración que le hace su hermano Yaaqob? A veces nos encontramos con precisiones como: "Simi" y agrega "de lah 'ikhah soltera (batulah) de Mimún Ben Hamu, nietah delah que blanqueah el qampo" o al lado del nombre del padre del circuncidado, Yosef, figura “'ikho de Maqni».

Sabemos la situación difícil de la mujer en Marruecos y en Tetuán porque de ello han dejado constancia los archivos de la AlU. Mujeres que a veces se quedaban con la tutela y la responsabilidad de sacar a sus hijos adelante mientras marido, hijos mayores emigraban a Latinoamérica sin que a veces llegasen ni dinero ni noticias del los emigrados.

\section{OFICIOS Y TRABAJOS DESEMPENAADOS POR LOS JUDIOOS DE TETUÁN SEGÚN EL LRC}

Del estudio de los oficios desempeñados por los padres de los circuncidados que aparecen en nuestro Libro Registro, se obtienen una serie serie de datos que permiten conocer la sociología económica de la comunidad de Tetuán entre 1881 y 1940.

De los 2725 registrados, hay 403 de los que no proporciona detalles sobre su oficio o profesión, pero si del resto, 2322. De la lectura de los trabajos desempeñados por los habitantes de Tetuán (gráfico 8), podemos concluir que se trataba de una comunidad con actividades artesanales, donde predominaba el sector primario de la economía y que dado el tipo de oficios desempeñados no es de extrañar la pobreza de la que tenemos datos en los archivos de la Alianza Israelita, que motivan que en muchas ocasiones hubiera que atender a las más elementales necesidades de los alumnos, como son las de vestir o comer.

42 José Benaim, de la C. Israelita de Madrid, piensa que se trata del nombre, lo cual es sorprendente por el hecho de conocer a un varón por la precisión del nombre de su hermana. 


\section{Gráfico 8}

\begin{tabular}{cc}
\hline RABINOS & 21 \\
NO RABINOS & 2704 \\
\hline
\end{tabular}

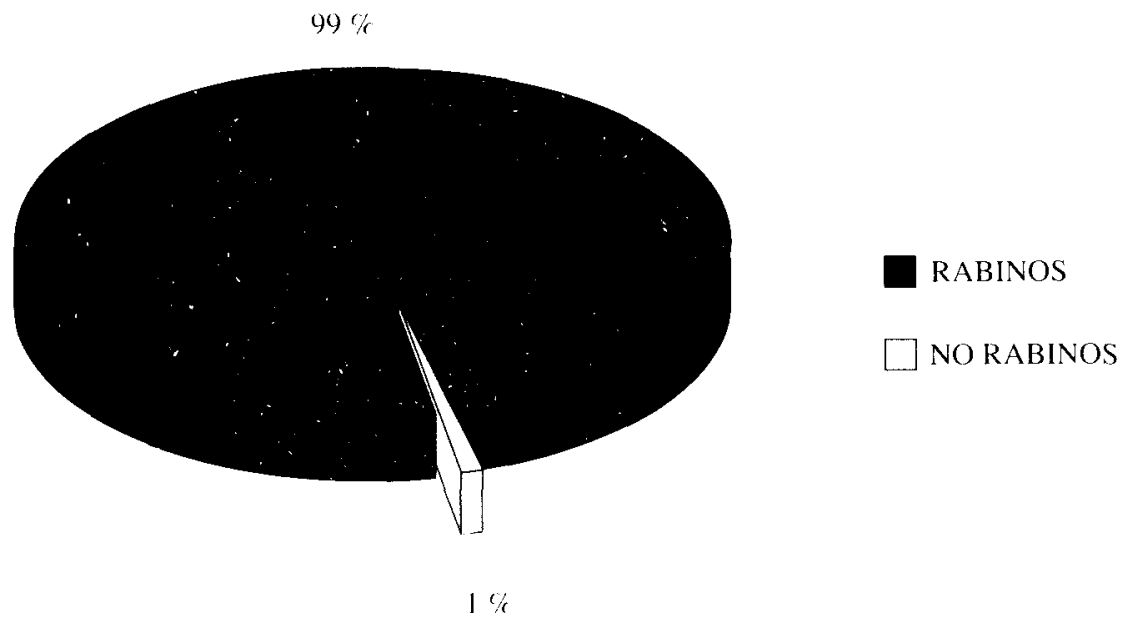

Los datos que el LRC nos proporciona en relación con la vida religiosa de la comunidad, 21 rabinos (gráfico 7), de los cuales 2, además actuaban de sofer ${ }^{43}, 23$ eran melamedim ${ }^{44}$ y 10 sohetim ${ }^{45}$, trabajo apreciado en la comunidad y realizado por aquellos rabinos que no tenían una situación económica desahogada que realizaban otros trabajos remunerados para poder sobrevivir. Había 3 de los que sólo precisa "que meldaban», 1 pay$\tan ^{46}, 14$ estudiaban en la $y$ sibah $^{47}, 4$ en la de Yagdil Torah ${ }^{48}$. La formación de los judíos tetuaníes hizo que se creasen instituciones para el estudio de la $\operatorname{Torah}^{49}$, como la de Yagdil Torá, considerada como "sagrada

43 "Escriba", el que escribe sobre pergamino el texto de la Torá, las filacterias o los versículos 4-9 del capítulo 6 y los números $12-20$ del 11 del Deuteronomio que se colocan en las jambas de las puertas guardados en un receptáculo que se toca al entrar y salir de la casa.

44 "Maestros de escuela".

45 "Matarife oficial", conocedor de las leyes que regulan la forma de sacrificar a los animales.

46 "Poeta litúrgico".

4. "Escuela rabínica".

48 Antes sinagoga de Yomtob Ha-Levi o del qahal, según I. Benatar. Hoy es la única sinago ga que sigue en funcionamiento.

${ }_{49}$ Torá o Ley es el fundamento del judaísmo. Está constituida por los cinco libros que los cristianos Ilaman Pentateuco. 


\section{Gráfico 7}

\begin{tabular}{lc}
\multicolumn{1}{c}{ OFICIOS } & N. ${ }^{\circ}$ de apariciones \\
\hline Comerciante & 348 \\
Camalo=mulero, transporta mercancias y viajeros & 210 \\
Tendero & 130 \\
Hornero & 75 \\
Zapatero & 68 \\
Baqual=especiero & 62 \\
Carpintero & 62 \\
Latero & 61 \\
Tienda en la alcaicería & 61 \\
Arriero & 58 \\
Jodrero=verdulero & 57 \\
Tienda de géneros & 55 \\
Platero & 52 \\
Albardero & 50 \\
Tarráf=remendón zapatero de viejo & 50 \\
Pintor & 47 \\
Va a las aldeas & 34 \\
Xellal=Xellear; trabajador temporero, no especiali & 34 \\
Cahguachi=cafetero & 30 \\
Sastre & 30 \\
\hline
\end{tabular}

\section{OHICIOS MÁS REPETIDOS}

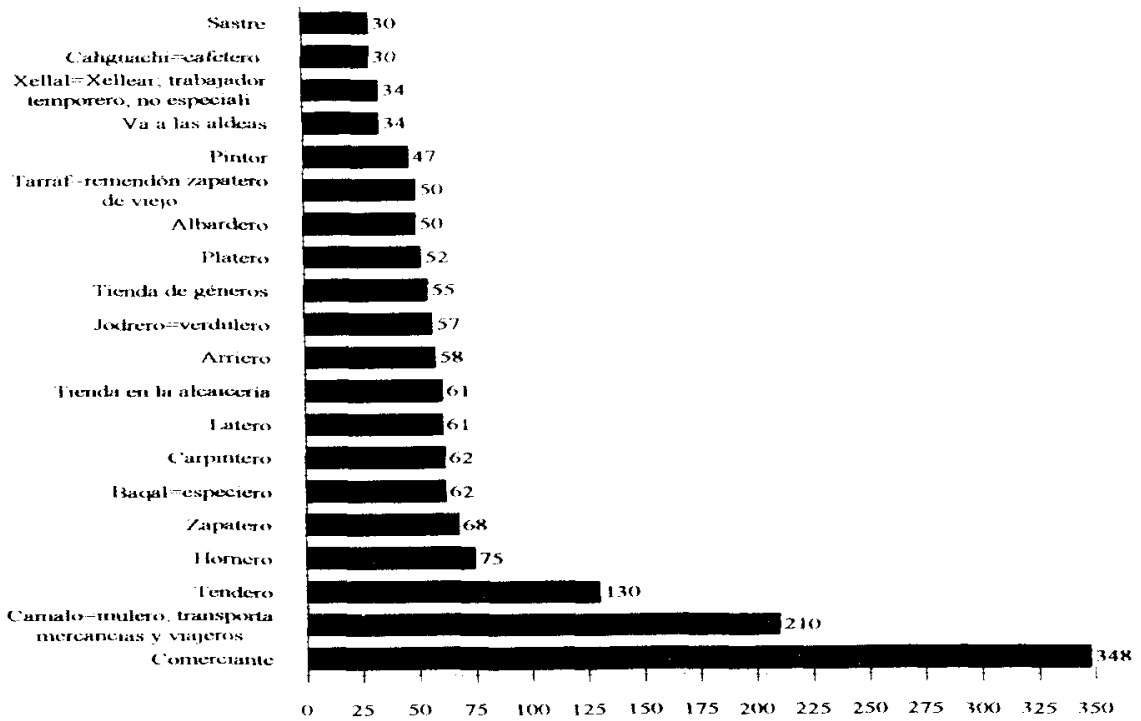


obra ... objeto de ... constantes desvelos", cuya misión era "proporcionar a los que se dedicaban al estudio de nuestra religión los medios necesarios para poder vivir medianamente siquiera pudiendo así dedicar ellos todo su tiempo a estudios religiosos" 50. Para ello en el boletín de esta Sociedad, entre los años 5673 y 5680 existe un listado de donaciones de Tetuán, Tánger, Ceuta y de otros lugares de Marruecos, así como de París, Buenos Aires, Argelia, etc. ${ }^{51}$. Asimismo tenemos 27 shamásh ${ }^{52}$, en uno de ellos especifica "shamásh de Qrudo (alude a la sinagoga con este nombre), y otro "shamásh del qahal ${ }^{53}$ » (es decir la de Yomtob Levy, según hemos indicado).

Hay trabajos desempeñados por los judíos de Tetuán que pueden indicar una mejor preparación y consecuentemente una mejor situación económica, es el caso de los cónsules en número de 9, uno de ellos "cónsul americano"; 3 banqueros; 2 practicantes; 16 cambistas; 40 plateros; 1 joyero y 4 que trabajan el oro viejo. Los joyeros de Fez o de Mogador gozaron de una reputada fama a lo largo de los siglos por "su orden, actividad e iniciativa" ${ }^{54}$. Asimismo trabajaron el hilo de oro y de plata, con los que efectuaban trabajos de gran calidad. Igualmente el comercio del oro, ejercido por los serraf o sarraf, cambistas a los que aluden varias taqqanot ${ }^{55} \mathrm{u}$ ordenanzas ${ }^{56}$. Asimismo, 1 director de escuela (se trata de Nisim Levy que llegó a Tetuán en 1892 procedente de los Dardanelos, después de la dimisión de $\mathrm{H}$. Hassán). Su hijo aparece circuncidado en 1896, y 2 profesores (uno es Yishaq 'Abudarham padre de Yhudáh, circuncidado en 1889 y el otro es Hayyim Hassán, padre de Shlomoh circuncidado en 1890). Supongo que fue posteriormente a esta fecha cuando fue nombrado director de la escuela), y 1 dentista. También encontramos 4 "entrepite» 0 intérpretes y dos «mursah» o procuradores.

50 Alegria BENDELAC, Los Nuestros. Sefiná, letuarios. Jaquetia y Fraja. Un retrato de los sefardies del Norte de Marruecos a través de sus recuerdos y de su lengua (1860-1984), N. York, P. Lang, 1987. pág. 203. José Benaim en un capítulo de sus memorias (inéditas), habla de como su bisabuelo materno Moisés Hachuel fundó en 1902 este Centro de Enseñanza judía de corte más moderno y abierto que los existentes en ese momento eri Tetuán.

51 A. Bendelac, op. cit. pág. 286.

52 "Sacristán".

53 «Comunidad judía».

54 Sarah Lelbovici, Chronique des Juifs de Tétuan (1860-1896), Paris, Maisonneuve \& Larose, 1984.. pág. 153.

55. Haim Zafrani, Mille ans de vie juive au Maroc. Histoire et cuiture. religion et magie ... Paris 1983. pág. 154

56 Cuerpo jurídico por el que se rigen las comunidades judías. En 1432 se reunieron los rabinos representantes de las aljamas de Castilla en Valladolid y redactaron las famosas taqqanot que despué influirán en las nuevas legislaciones de las comunidades que formen los expulsados después de 1492 . 
El gran conjunto de la población desempeñaba otro tipo de oficios más comunes como el de "comerciantes", primero de los oficios más desempeñados por los judíos de Tetuán según el Libro Registro de Circuncisiones, en el que aparecen en número de 393, sin especificar a que tipo de actividad se dedicaban, sólo en 18 casos nos habla de "comestibles". En otros casos dice que eran "compradores en el zoco", sin especificar de qué, en un caso indica que es "comprador de hierro" y en tres de "salvado", ya que entre otros trabajos se ocuparon del comercio de los cereales ${ }^{57}$, sobre todo del grano que producian sus propias tierras o el de aquellos que lo entregaban como pago de los préstamos recibidos. Los cereales o se exportaban o se almacenaban en en una especie de silos para el consumo. Los particulares también los almacenaban en depósitos especialmente preparados para guardar alimentos. Sorprende su dedicación a la agricultura en este periodo previo al que es objeto de este estudio, porque contribuyeron a renovar el panorama agrícola e intentaron pasar de una agricultura tradicional a intentar adaptar nuevos productos como el algodón, aunque no tuvieron éxito. A veces se encuentra esta dedicación al comercio aunque sin especificar las mercancías con las que comerciaban, 10 que manifiesta con las expresiones: "va a Gibraltar y viene», 7; "va a España", "va a las aldeas» (para compra y venta de productos varios), 29; "va a Ceuta y viene", 4; "va al Rif», "va a Alcázar». Hasta 1904, los judíos comerciaban también en otros barrios de la propia Tetuán. Así por ejemplo, de los citados se dice: "Va Tal'a", barrio árabe de Tetuán, según nos indica Isaac Benatar de la $\mathrm{C}$. Israelita de Madrid. Igualmente los que denomina «negociantes, en un total de 11. Tampoco especifica el tipo de negocios, salvo en uno que indica «negociante en trigo". En tres ocasiones indica el lugar del negocio, "Caracas", Gibraltar», "Xauen».

Otro de los trabajos más comunes es el de "tendero" (tercer trabajo de los judíos de Tetuán), con 264 casos. El 127 de los registros no especifica cuál era el producto que se vendía en la tienda. En 53 casos habla de "tienda de géneros", en uno de "comestibles, en dos, "tienda de quincalla", en otros dos de "tabacos" con la variante "estanco de tabacos", 60 tienen una tienda en la alcaicería, barrio cerrado en el que estaba el comercio principal de la población y que estaba cubierta con un espeso toldo de cañas, y comprendía más de trescientas tiendas... Éstas como todas las de Marruecos, eran una especie de alacenas embutidas en la pared, dentro de las cuales se sentaba el mercader sobre las piernas cruzadas,

Haim Zafrani, Mille ans de vie ... op. cit. pág. 150. 
teniendo al alcance de su mano todas las mercancías ${ }^{58}$ y donde se comerciaba con todo tipo de productos (foto $n .{ }^{\circ} 3$ ).

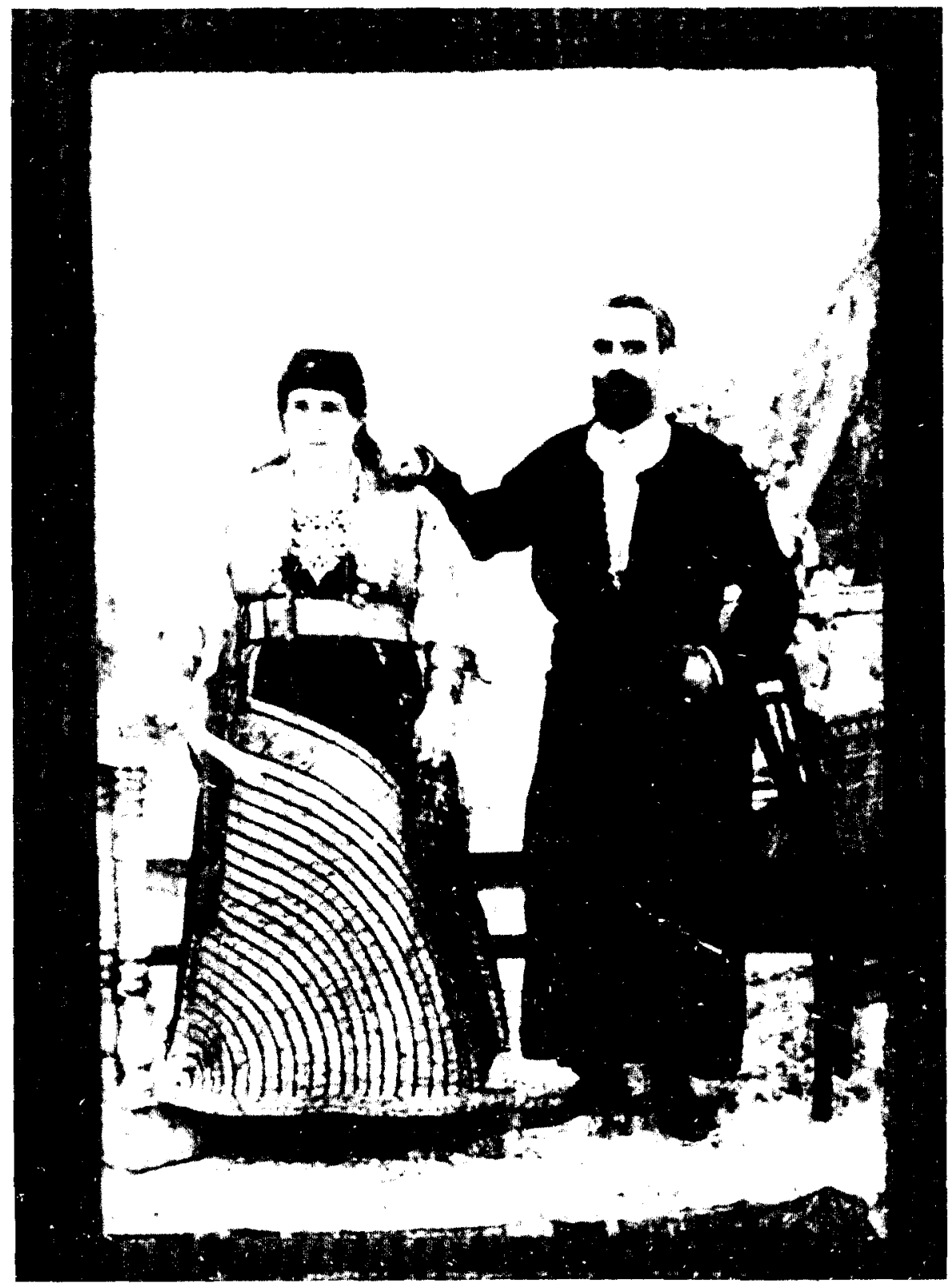


Encontramos asimismo, 47 "vendedores". Con esta denominación general, se recogen las ventas de cosas varias: "frutas", "habas cochas", "huevos», "leche-queso", quincalla», "hierro", "cereales", "muebles", "periódicos, lotería». Pero existen otro tipo de vendedores como los «jodreros", o verduleros, que venden verduras, de los que encontramos 57. Pero los judíos de Tetuán necesitaban también albardas, y así nos aparecen 47 "albarderos»; 26 "alhalueros", o vendedores de dulces, vendían alhalua "traía dulces de berengenas, azahar" ${ }^{59} ; 2$ vendedores de "fakias", (cacahuetes, nueces, pipas, etc.) ${ }^{60} ; 2$ "vendedores de buñuelos", 3 "bengoeleros»o buñoleros 2 que «hacen buñuelos»; 60 «baqal» o especieros; 5 "chalafis" o jaboneros; 7 "molineros"; 26 "qahguachi» o cafeteros; 72 "horneros", encargados de elaborar el pan para la comunidad; algunos desempeñaban otro trabajo, asi 5 eran camalos ${ }^{61}$ y 1 qahguachi. A ellos hemos de añadir, 16 "duguas, 0 duuas", vendedores ambulantes de telas y tejidos ${ }^{62}$, o los »dellal», 15 , que iban por la calle "pregonando la última puja, de objetos de todas las clases que les eran confiados para este fin» ${ }^{63}$. También hay "compradores" en número de 27 , de 14 dice "comprador en el zoco», 7 "de salvado", 4 «de huevos», 1 "de hierro» y 1 «de trigo". Parece que el cereal era importante para los judíos de Tetuán, así de 7 dice «del zoco del trigo» y de 11 "en el zoco del trigo".

Pero las mercancías que se ponían a la venta, era necesario transportarlas y muchas de ellas llegaban a la aduana de Río Martín. Los comerciantes se desplazaban de un lugar a otro para sus transacciones comerciales, por ello eran necesarios los "camalos", muleros o transportistas tanto de mercancías como de viajeros. Fue una ocupación específica de los judíos de Tetuán, entre esta ciudad y Tánger ${ }^{64}$ y que dedicados a esta actividad aparecen en este trabajo en número de 210 (segundo trabajo

58 P. Antonio de AlaRCón, Diario de un testigo de la guerra de África, Tomo II, págs. 80-85.

59 A. Bendelac, op. cit.., págs. 38, 288, 391; Alegría Bendayan de Bendelac, Diccionario del Judeoespañol de los Sefardies del Norte de Marruecos, Caracas, 1995, pág. 24: «dulce moruno hecho con almendras, o cacahuetes o sésamo, mezclado con caramelo bien oscuro".

60 A. Bendelac, op. cit.., pág. 336. Alegría Bendayan de Bendelac, Diccionario ... op. cit, pág. 264: «mezcla de fruta seca y nueces (nueces, higos, avellanas, pasasa, dátiles, cacahuete, garbanzos tostados, etc.)".

61 Alegría BendayAn de Bendelac, Diccionario ... op. cit., pág. 103: "descargador, mozo de cordel, azacán, hombre alto y fuerte que hace trabajos duros".

62 José Benoliel, Dialecto judeo-hispano ... op. cit., pág. 192, Alegría BendayAn de BENDELAC, Diccionario ... op. cit. pág. 216.

63 José Benoliel, Dialecto judeo-hispano ... op. cit., pág. 189. Alegria Bendayan de BendelaC, Diccionario ... op. cit pág. 179.

64 Juan Bta. VILAR, Tetuán en el resurgimiento judío contemporáneo (1850-1870). Aproximación a la Historia del Judaismo Norteafricano, Caracas 1985. pág. 136. 
más desempeñado, según el Libro Registro de Circuncisiones). En una parte importante, 79 , desempeñaban su trabajo entre Tetuán y la aduana de Martín. De ellos, 3 desempenaban otras actividades, como shamásh ${ }^{65}$, cahguachi y 'aarrad o «invitadores de viva voz a los acontecimientos de la comunidad: las fiestas, bodas y circuncisiones» ${ }^{66}$, en número de 6 , y 2 camareros. Junto a ellos aparecen los «arrieros" en número de 57 , de los cuales, sólo en el caso de 11 nos habla de dónde desempeñan su trabajo. Cinco son arrieros en Ceuta, 4 en Martín y 2 en Tánger.

Otro oficio desempeñado por los judíos de Tetuán era el de «zapatero", 75 aparecen desempeñando este trabajo con esta denominación, por lo que me inclino a creer que eran los que realizaban el calzado. Aparece como el quinto oficio desempeñado por los judíos tetuaníes. Al lado de ellos aparecen los tarraf en número de 49 que son los remendones o "zapatero viejo", en definitiva los que arreglan los zapatos pero también los que hacían un tipo de tosco calzado moro para los campesinos y 9 "betuneros" o limpiabotas.

También hay "lateros", en número de $61 ; 12$ "asufareros» que trabajan el azófar o el latón ${ }^{67} ; 7$ "trabajan la piedra», 2 en la me'ará, cementerio.

Otros trabajos desempeñados por los judíos tetuanies eran el de "sastres», 30; "carpinteros" o nichar, 62; barberos 20 (además otros 23 que aparecen como "halaq"); "babucheros", 3; "que hacen baúles", 5. También existieron cardadores o "qardas o qadras" de lana, 6; carniceros 21 , que diferencia de los que trabajaban en "la guerna" ${ }^{68}$, matadero en número de 7 y de los que "traen la carne". El tabaco era uno de los productos con los que se traficaba pero también existieron otros ${ }^{69}$. El monopolio del comercio de tabacos era adquirido por numerosos comerciantes judíos pagando una taxa al Tesoro real ${ }^{70}$. En el Libro Registro de Circuncisiones, aparecen desempeñando el oficio de "cigarreros", 7. También tenemos, "albañiles», 14;" basureros" 6;46 «pintores", es de suponer que de "brocha gorda»; 8 relojeros"; 4 "'esqot», que "venden ...", pare-

\footnotetext{
65 Doméstico, servidor. Sacristán, bedel

66 A. Bendelac, op. cit., págs. 39, 294-95, 338 y 415.; Alegría Bendayan de Bendelac. Diccionario ... op. cit. pág. 762 .

67 J. BENOLIEL, Dialecto judeo-hispano ... op. cit., pág. 176.

68 Haim Zafrani, Los judios del Occidente musulmán. Al-Andalus y el Magreb. Madrid, 1994, pág. 290.

69 Juan Bta. VILAR, Tetuán ... op. cit., pág. 162:»El trasbordo de mercancias ilícitas solía hacerse en la desembocadura del Martín, mediante barcazas al objeto de evitar los controles aduaneros, o bien en alta mar».

${ }^{70}$ Haim Zafrani. Mille ans de vie ... op. cit. pág. 151.
} 
ce que se refiere a los menudillos del animal, lo que habitualmente hoy se vende en la casquería, según José Benaim.

Otros oficios aparecen con menor asiduidad en el Libro Registro, como el de "cocinero", 1 ; "Cobradores de la luz", 2; "Cobradores en la botica» (farmacia); "chófer de Toledano", 1; "del billar", 3, «despacha los autos" (factura, vende billetes en cualquiera de las compañías que existieron en Tetuán: La Unión, Minerva, La Valenciana); los siguientes oficios sólo tienen 1 representante: "fotógrafo", "el que hace fuelles", "muebles", "portero de escuela», "teatro" (según José Benaim no es que fuese actor sino que colocaría los carteles que anunciaban las funciones de cine o de teatro); «en la contrata del polvo" (contratata similar a la del tabaco pero en este caso de rape al que eran tan aficionados los tetuanies), aparece 1 sólo representante. Los "que hacen peines», para cardar la lana, son 8; los que regentaron una fonda 3 ; "comisiones» o "comisionista», 11; "representaciones", 1, y 11 quincalleros. Un «ta'ayyanero", tainero. Puede derivar del árabe ta'an, atacar, criticar, sacar defectos a un juicio. Podría ser "criticón», con el sufijo español "ero". José Benaim nos indica que se trata de un "tallador de piedras". ¿preciosas?. Existen 8, que según Rabí Ha-erfaty al referirse al trabajo u oficio que desempeñan, indica "sinías", "aze sinias", según Isaaac Benatar de la C.I. de Madrid, se refiere a aquellos que hacen bandejas doradas de distintos tipos, modelos y tamaños. J. Benoliel ${ }^{71}$, lo recoge como palabra árabe. También tenemos los que "'abren qanios» que no llegaban a ser fontaneros pues eran especie de albañiles que desatascaban la cañerías. También en una caso nos aparece "Yishaq hijo de Moshi el del qarro", especie de carretilla para transportar muebles $u$ otros enseres.

Quiero hacer un apartado para los que denomina "empleados», en número de 30 que salvo uno que "trabaja en la luz eléctrica", no sabíamos el tipo de empleo que desempeñaban, ya que las especificaciones no son en la mayoría de los casos claras. Sin e mbargo en esta parte hemos encontrado la ayuda inestimable de Isaac Benatar y José Benaim ${ }^{72}$.

empleado «con Benaar» (tienda de comestibles, almacén al por mayor);

empleado "con Yosef Benarós", (quien era «propietario»), 1 empleado;

empleado "con Nissim Garshón» (agencia de aduanas), 1;

empleado "on Saadía", (quien tenia una tienda de "comestibles finos", según Isaac Benatar, "El amigo de todo"), con él tenemos 1 empleado;

J. BENOLIEL, Dialecto judeo-hispano ... op. cit. pág. 249: «ar. batea.

Miembros de la C. Israelita de Madrid y tetuaníes y a los que ya me he referido: 
3 aparecen con "Yshu'a»; 4 en la "escuela»; "en un banco»; "en el juzgado";

en «la tienda de Shlomoh erfaty» (tienda París-Tetuán, tejidos, ropa confeccionada, un poco de todo, en palabras de José Benaim "un Corte Inglés");

"en un café», 3; 1 en "el café de La Luneta" (famosa calle del mellah ${ }^{73}$ donde existieron dos cafés el Royal y el Gambrinos); "en una fondah de euah";

"está con Yosef 'Abudarham" (bazar);

"con León Ma'amán" (quien tenía un almacén de comestibles donde se vendía: harina, azúcar, aceite, etc.);

"está con Toledano", quien era banquero, supongo que llevaría sus cuentas, contable;

"está en el garaje de Ben olón", tenemos dos que trabajan en este garaje, que era, según Isaac Benatar, un lugar que servía como hoy, para guardar los coches; "está con 'Ab Yishra'el»; 4 «en el billar;

4 en «El Correo Inglés", según me ha indicado B. Garzón ${ }^{74}$, se trataba de una estafeta de Correos concedida a los ingleses, donde, durante la 2. ${ }^{\circledR}$ Guerra Mundial, se recibian, la prensa y noticias sobre la situación de los aliados. No se puede olvidar que Tetuán estaba dentro de la zona del Protectorado Español y por tanto más cercana al gobierno alemán ${ }^{75}$.

En "La Caraqueña», tienda de tejidos de Tetuán que estaba en la calle Mohamed $V$ y anteriormente calle del Generalisimo, había 4 empleados.. Era de un iniembro de la familia Benolón que emigró a Venezuela y que cuando volvió fundó la tienda.

También en "La Gaceta [de África»], periódico de la zona existía un empleado.

No podemos saber si en todos los casos este tipo de trabajo requería especialización. Nos inclinamos a creer que no. Sin embargo al referirse al oficio de su padre, R. Vidal, nos indica que era "empleado, shekh», jefe de la comunidad, director.

\footnotetext{
73 "Barrio judio" en Marruecos. El mellah segúm la ENCICLOPEDIA UNIVERSAL ILUSTRADA... Tomo LXI, Madrid, Espasa Calpe, 1928: "el Melaj o Mellah (el Saladero) ... lo forman dos calles paralelas, rectilineas, cortadas perpendicularmente por otras mmás estrechas; algunas cubiertas, todas muy aseadas ... limitado por la acequia Sakia el Fokia... Los apellidos Pariente, Toledano, Taurel o Teruel, Moreno, Pinto, León, Laredo, Ribas, de origen español, sellaron la iniciativa urbana del mejor organizado distrito del Tetuán antiguo. Las calles recibieron el nombre de Kaisería, Prado, Las Griyas, Aniyi, del Huerco, de Maimón, de los Bañadores y de las distintas sinagogas que aparecian para el culto mosaico ... Las sinagogas de esta judería son 16 .... Ernesto JIMENEZ CABALLERO, "La casa de un banquero", Raices primavera 1994, pág. 33: "El barrio es una fortaleza con tres puertas sólo de relación al exterior; las calles son estrechas y sin recovecos ... Las casas muy altas, con enrejados ventanillos abiertos en las alturas ..."

74 A la ayuda de Benatar y Benaim, se ha unido la de R. Benito Garzón de la C.I. de Madrid.

is Agradecimiento a R.B. Garzón de la C.I. de Madrid.
} 
También aparecen los que no tienen un trabajo determinado, "sin profesión", 5 o los que denomina "xellal», que no son más que trabajadores de temporada, no especializados, "hace mandados", "hace serviles» En este grupo he incluidolos que R. Ha-erfaty denomina, "trabajadores", en un total de 6 .

Las mujeres también desempeñaron trabajos temporales, generalmente como "sirvientas", particularmente en aquellos casos en que eran madres solteras. Eran apreciadas porque eran muy trabajadoras. Como sirvientas eran muy consideradas. También se las solicitaba como enjabelgadoras, así en el registro 1108, la madre del circuncidado, Simi, era nieta de «la que blanquea en el campo", costureras, cocineras y planchadoras. En el libro de Registro, aparecen mujeres que se dedicaban a algunos de estos menesteres, según hemos comentado.

También la emigración aparece reflejada en el LRC en especial a Brasil,Venezuela y Argentina (gráfico 9).

Ceuta

Tánger

Alejandria

América

Brasil

Buenos Aires

Caracas

Melilla

España (Sevilla, Madrid, La Linea)

Lisboa

Casablanca

Gibraltar

Rif

América (sin especificar)

Otros lugares
19

3

1

4

17

7

33

2

8

1

1

11

1

4

11

Según el Libro Registro objeto de este trabajo, de la población masculina con hijos varones se encontraba emigrada. un $5 \%$ aproximadamente.

Conclusiones sobre la comunidad judía de Tetuán en este periodo. estudio de los datos sociológicos de la comunidad sefardi de Tetuán aportados por el LRC de R. Bar Vidal Ha-Serfaty nos permite concluir que: 


\section{Gráfico 9}

\begin{tabular}{lc}
\hline \multicolumn{1}{c}{ LUGARES DE EMIGRACIÓN } & N. de apariciones \\
\hline Caracas & 33 \\
Brasil & 21 \\
Ceuta & 19 \\
Gibraltar & 11 \\
Buenos Aires & 7 \\
España & 5 \\
América & 4 \\
Otros & 16 \\
\hline
\end{tabular}

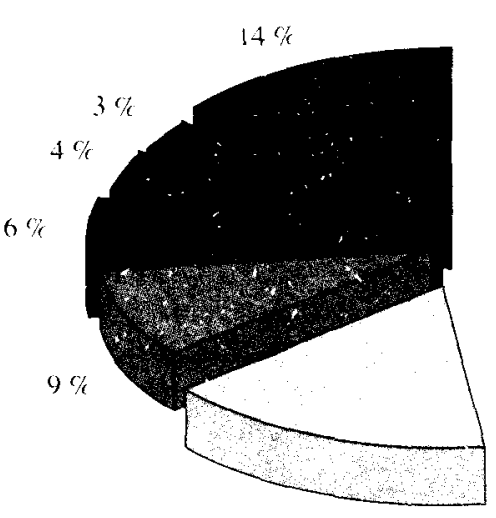

$16 \%$
Caracas

Brasil

$29 \%$

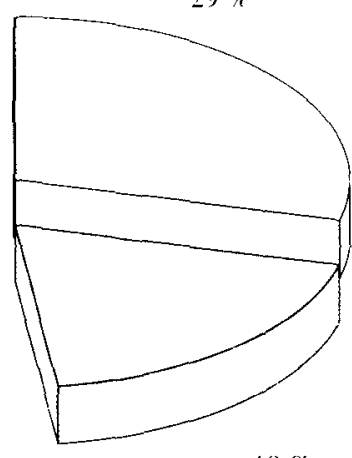

$19 \%$

$\square$ Ceuta
Gibraltar

- Buenos Aires

España

América

Otros

- Había un fuerte predominio del sector primario en la economía de la comunidad, que se mantuvo a través del tiempo sin variaciones.

- Endogamia, motivada por la falta de comunicación con el exterior, salvo los dos años de dominación de los españoles (1860-1862), la AlU, y el Protectorado, pero sobre todo por su propia idiosincrasia.

- Evolución en el siglo xIx.

- Importancia de España. El Protectorado. Permanericia de la población sefardí de Tetuán durante éste.

- La emigración, que tuvo como objetivo primero zonas próximas: Ceuta, Orán, Melilla, Gibraltar, la Península y más tarde Argentina, Brasil, 
Venezuela,que comienza en la segunda mitad del siglo $x I x$, continúa en el $x x$ y sobre todo a partir de la independencia de Marruecos en 1957, donde Canadá, EEUU, América del Sur, Francia y España (Madrid, especialmente) y los que tenían menos posiblidades a Israel,lo que dará al traste con una de las comunidades sefardies mas importantes del Norte de Marruecos.

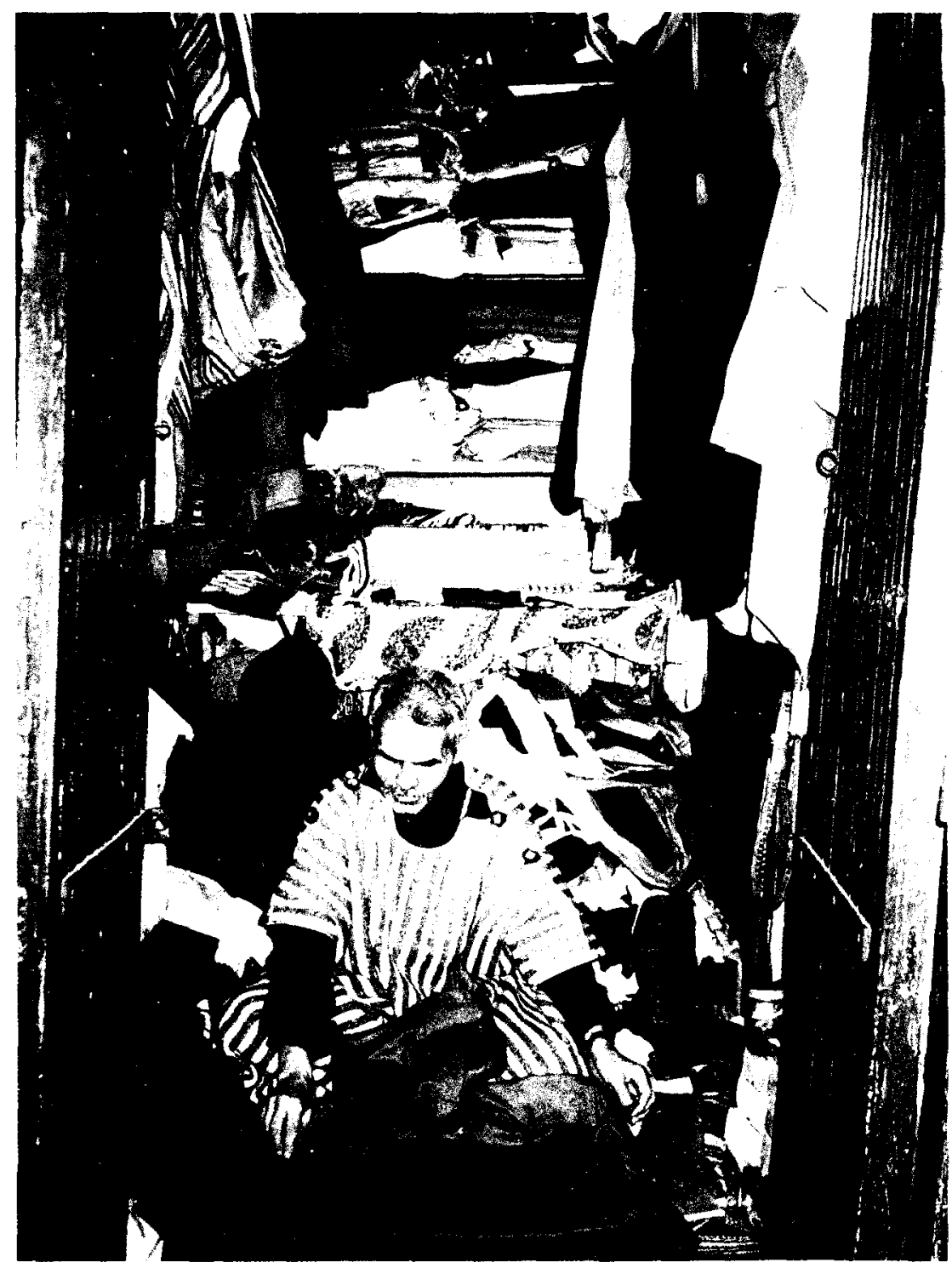

